\title{
Origins of Grape and Wine Aroma. Part 2. Chemical and Sensory Analysis
}

\author{
Anthony L. Robinson, ${ }^{1,2}$ Paul K. Boss, ${ }^{3}$ Peter S. Solomon, ${ }^{4}$ \\ Robert D. Trengove, ${ }^{1}$ Hildegarde Heymann, ${ }^{5}$ Susan E. Ebeler ${ }^{5 *}$
}

\begin{abstract}
Part 1 of this review summarized the current state of knowledge with respect to the chemical compounds contributing to grape and wine aroma. Much of our understanding of the chemistry of grape and wine composition comes from advances in analytical and sensory methods for identifying and quantifying the compounds that contribute to flavor. Therefore, Part 2 of this review provides an overview of the chemical and sensory analysis approaches that have been used to deconstruct wine flavor into its component parts with an aim toward relating the chemical composition to the unique sensory properties that are associated with different wine varieties and styles.
\end{abstract}

Key words: gas chromatography-mass spectrometry, multidimensional separations, sample preparation, sample extraction, GC-olfactometry, sensory descriptive analysis

Part 1 of this review provided an overview of the chemical components in grapes and wines and the viticultural, winemaking, and storage practices that influence their formation and concentrations. In Part 2 we provide a summary of the analytical chemistry and sensory approaches for assessing wine flavor. As noted previously, we have attempted to be as complete as possible, however, given the numerous publications in these areas, not all research can be covered (e.g., a Google Scholar search for the phrase "analysis of wine flavor" returns $>6,600$ publications from the years 2012-2013; the phrase "sensory analysis of wine flavor" returns $>5,600$ publications over the same period). Therefore, we have chosen to focus on selected recent applications to demonstrate the power and types of information that can be obtained with current analytical and sensory approaches. The reader is also referred to several reviews for more detailed discussions of selected topics (Francis and Newton 2005, Lesschaeve 2007, Plutowska and Wardencki 2008, Polášková et al. 2008, Ebeler and Thorngate 2009, Muñoz-González et al. 2011, Ebeler 2012).

\section{Chemical Analysis of Aroma and Flavor Compounds}

Essential to understanding the various influences on wine flavor is the ability to purify, identify, and quantify the com-

\footnotetext{
${ }^{1}$ Separation Science and Metabolomics Laboratory, Murdoch University, Murdoch, WA 6150, Australia; ${ }^{2}$ Treasury Wine Estates, P.O. Box 396, Nuriootpa, SA 5355, Australia; ${ }^{3}$ CSIRO Plant Industry, P.O. Box 350 Glen Osmond, SA 5064, Australia; ${ }^{4}$ Plant Science Division, Research School of Biology, Australian National University, Canberra, ACT 0200, Australia; and ${ }^{5}$ Department of Viticulture and Enology, University of California, Davis, CA 95616 USA.

*Corresponding author (seebeler@ucdavis.edu; tel: 530-752-0696; fax: 530752-0382)

Acknowledgments: The authors thank the Australian Grape and Wine Research and Development Corporation and the Australian-American Fulbright scholarship program for financial support for ALR.

Manuscript submitted Oct 2013, revised Dec 2013, accepted Dec 2013

Copyright $(\subset 2014$ by the American Society for Enology and Viticulture. All rights reserved.

doi: 10.5344/ajev.2013.13106
}

pounds responsible for the sensory attributes experienced by a wine consumer. Multiple techniques have been used for characterizing the composition of wine, including flame atomic absorption spectrophotometry and flame atomic emission spectrophotometry (Frías et al. 2003), inductively coupled plasma mass spectrometry (Baxter et al. 1997), liquid chromatography (LC) (Bellomarino et al. 2009), gas chromatography (GC) (Marengo et al. 2002), UV, visible, near-infrared, and mid-infrared spectroscopy (Liu et al. 2006, Cozzolino et al. 2010), nuclear magnetic resonance spectroscopy (Brescia et al. 2002), and electronic nose (Cynkar et al. 2010). Because $\mathrm{GC}$ can separate the volatile compounds in a complex mixture, providing quantitative information as well as the ability to tentatively identify compounds based on their retention times (which reflect the boiling point and polarity of the analytes), the majority of studies assessing volatile compounds that contribute to aroma have used GC methods.

\section{Gas Chromatography and GC-Mass Spectrometry}

Gas-liquid chromatography (GC) was developed in 1952 (James and Martin 1952). Initial GC separations used relatively short (3-10 $\mathrm{m}$ length, $\sim 2 \mathrm{~mm}$ i.d.), packed columns that separated only a few compounds in complex mixtures. For example, an early wine application separated 10 fusel alcohols in wine distillates (Webb and Kepner 1961). The introduction of fused-silica capillary columns in 1979 (Dandeneau and Zerenner 1979) provided increased chemical inertness and the ability to reproducibly produce very long (30-100 $\mathrm{m})$ and very narrow diameter $(0.25-0.32 \mathrm{~mm})$ columns. This resulted in significantly improved efficiencies and the ability to reliably separate hundreds of compounds, many present at trace levels.

Numerous GC detectors are available, including flame ionization, which detect all molecules containing reduced carbon (i.e., -CH-); nitrogen phosphorous, which specifically detect only molecules containing $\mathrm{N}$ or $\mathrm{P}$; sulfur chemiluminescence or flame photometric, which specifically detect only molecules 
containing S; and mass spectrometer (MS), which detect ionized molecules based on the ratio of their mass to charge. GCMS has significant advantages for compound identification relative to other GC detectors and analytical techniques due to the availability of extensive mass spectral and retention index databases (Stein 1999, Babushok 2007). This, in addition to the fact that the costs of bench-top and user-friendly mass spectrometers have become more affordable for the majority of users, has made GC-MS analysis among the most widely used methods for analysis of wine flavors.

Mass spectrometry was discovered by J.J. Thomson in the early 20th century and was developed by F.W. Aston in 1919, who demonstrated the existence of isotopes in non-radioactive elements (Aston 1919). Modern commercial GC-MS instrumentation combines compound ionization, resulting in unique mass spectral fragmentation patterns, with high-resolution separation of the resulting ions, and selective and sensitive mass detection. Numerous reviews discuss various aspects of wine composition with an emphasis on the role that GC-MS analysis has played in contributing to current knowledge in the field of wine and grape chemistry (Schreier et al. 1976, Ebeler 2001, 2012, Ebeler and Thorngate 2009, Hayasaka et al. 2005, Polášková et al. 2008).

Contemporary MS detectors include various instrument configurations and types of mass analyzers, including transmission quadrupole, ion trap, and time of flight. Tandem MS (MS/MS) detectors also offer distinct advantages for sensitive and targeted analysis of known compounds.

Transmission quadrupole mass analyzers use four parallel, hyperbolic rods (electrodes) (Murray et al. 2013). Opposing pairs are connected to each other and a radio frequency and direct current voltage are applied alternately across the rods. Ions oscillate in the field with a frequency dependent on the ratio of their mass to charge $(\mathrm{m} / \mathrm{z})$. As the radio frequency voltage is varied, only ions of a specific $\mathrm{m} / \mathrm{z}$ will have a stable trajectory through the quadrupoles to the detector. Quadrupole ion traps (or Paul ion traps) are similar, with two ring-shaped electrodes (rather than cylindrical rods) and two end-cap electrodes (Murray et al. 2013). A radio frequency field is applied and ions are spatially confined within the electrodes with a cyclic motion. By scanning the radio frequency field, ions of a given $\mathrm{m} / \mathrm{z}$ are excited, ejected through a small aperture in one end of the cap, and detected. Most quadrupole analyzers provide the ability to separate ions based on a mass difference of $1 \mathrm{amu}$. With time-of-flight (TOF) mass analyzers, ions leaving the GC interface and source are accelerated to the same kinetic energy. The ions then travel through a flight tube with a velocity that is proportional to the $\mathrm{m} / \mathrm{z}$ of the ion: that is, ions with different $m / z$ will travel at different speeds. TOF-MS instruments may provide unit mass resolving powers similar to those of quadrupole instruments; however, high-resolution TOF-MS instruments are also available that provide the ability to distinguish the mass of ions with much greater accuracy (e.g., ethyl acetate $\mathrm{m} / \mathrm{z} 88.1051$ and 1-pentanol $\mathrm{m} / \mathrm{z} 88.1482$ ). This can significantly aid compound identification. Fourier-transform ion cyclotron resonance (FTICR) mass spectrometers offer even greater mass accuracy.
With these instruments, ions leaving the source are captured in a magnetic field where they rotate with an angular frequency that is proportional to the magnetic field and inversely proportional to the ion mass (Murray et al. 2013). All ions are detected simultaneously and ions with different cyclotron frequencies (i.e., different $\mathrm{m} / \mathrm{z}$ ) are extracted mathematically through a Fourier-transform calculation.

The majority of wine flavor research applications have used unit mass resolution instruments (transmission quadrupoles, ion traps, or low-resolution TOF-MS). However highresolution GC-TOF-MS instruments are now commercially available and the number of published applications should increase over the next several years. The high cost of FTICR-MS has limited their application for wine flavor research, although several recent articles have emphasized the potential of this technique for identification of novel compounds, nontargeted profiling, and authentication (Cooper and Marshall 2001, Gougeon et al. 2009, Liger-Belair et al. 2009, CuadrosInostroza et al. 2010, Marchal et al. 2011).

Tandem mass spectrometry (MS/MS) uses more than one mass separation/analysis step, with mass separation occurring sequentially either in space or in time (e.g., ion trap instruments). In MS/MS analysis, ions from the first mass analyzer (MS1) enter into a reaction cell where they are bombarded with a reaction gas resulting in fragmentation of the ions (referred to as collision induced dissociation, CID, or collision-activated dissociation, CAD). The second mass analyzer (MS2) is then set to analyze selected fragments resulting from the fragmentation in the reaction cell. Several types of experiments can be performed depending on whether MS1 and MS2 are set to scan a range of $m / z$ or to filter and detect only ions of a given $\mathrm{m} / \mathrm{z}$ (see review by de Hoffmann 1996). Because each mass analyzer can be set to selectively analyze only peaks of a given $\mathrm{m} / \mathrm{z}$, effectively filtering out noise and nontarget analytes, MS/MS can be a highly sensitive and selective method for targeted analysis and quantification of trace compounds.

GC-MS/MS analysis is increasingly used for targeted analysis of aroma compounds in wines with particular emphasis on analysis of cork-taint related haloanisoles and volatile phenols produced by Brettanomyces (Pizarro et al. 2011a, 2011b, Hjelmeland et al. 2012, Collins et al. 2012). In other selected applications, MS/MS has also been used for trace analysis of odor-active polyfunctional thiols, quantification of rotundone as a function of grape maturity and winemaking practices, characterization of stereoisomers of wine lactone, analysis of furaneol and homofuraneol, and screening of aroma-active aldehydes (Schneider et al. 2003, Luan et al. 2006, Schmarr et al. 2008a, Masson and Schneider 2009, Caputi et al. 2011, Mattivi et al. 2011). MS/MS in combination with high-performance liquid chromatography (HPLC) has also been used to monitor the nonvolatile glycosidically bound aroma precursors in a number of studies (Fedrizzi et al. 2009, Hayasaka et al. 2010b, Capone et al. 2010, 2011, Kobayashi et al. 2011, Wilkinson et al. 2011). In an interesting application, HPLCMS/MS proved invaluable in the characterization of guaiacol conjugates in grapevine leaves and berries following exposure 
to stable isotope-labeled guaiacol ( $\mathrm{d}_{3}$-guaiacol), simulating smoke contamination of the vine (Hayasaka et al. 2010a). The $\mathrm{MS} / \mathrm{MS}$ profile of the isotopic doublets associated with the deuterated guaiacol conjugates enabled identification of seven different glycoside conjugates. In addition, translocation of the guaiacol conjugates between leaves and berries was observed. While not a comprehensive list of applications, these examples demonstrate the use of MS/MS for a wide range of flavor characterization studies.

\section{Multidimensional Separations}

While fused-silica, open-tubular capillary columns revolutionized GC separations, significantly improving column efficiencies and resolution, coelution of peaks in compound mixtures still frequently occurs. High-resolution accurate MS detectors and deconvolution software that can distinguish closely eluting peaks based on statistical differences in their mass spectra (Tikunov et al. 2005, Jiang et al. 2010, Furbo and Christensen 2012, Yang et al. 2013) can aid in peak identifications. However, improvements in chromatographic resolution through multidimensional separations have also received much attention. In early multidimensional separations, a chromatographic peak from a first separation column was passed onto a second column with a different stationary phase, via a switching or splitting device. Peaks that coelute on the first column are separated in the second dimension due to differences in interactions with the stationary phase on the second column. Often called "heart-cutting," this technique has been frequently used in wine applications to separate chiral analytes by using a chiral column as the second analytical column (Bouchilloux et al. 2000, Darriet et al. 2001, Fernandes et al. 2003, Barba et al. 2010).

More recently, the development of comprehensive twodimensional gas chromatography $(\mathrm{GC} \times \mathrm{GC})$ (Liu and Phillips 1991) has received significant interest for analysis of highly complex samples, including food, beverage, environmental, biological, and petrochemical (Adahchour et al. 2008). In $\mathrm{GC} \times \mathrm{GC}$ analysis, the column effluent of the first analytical column is trapped in small pulses and then quantitatively transferred to the second column. In this way, the entire set of analytes eluting from the first column is separated in the second dimension. Pulse times must be carefully selected to minimize peak splitting and to optimize transfer to the second column. GC $\times \mathrm{GC}$ offers enhanced separation efficiency, reliability in qualitative and quantitative analysis, capability to detect low quantities, and information on the whole sample and its components, as recently reviewed (Dallüge et al. 2003, Górecki et al. 2004, Ong and Marriott 2002).

$\mathrm{GC} \times \mathrm{GC}$ coupled with headspace analysis using solid-phase microextraction (HS-SPME) has been used to isolate volatile compounds from the sample matrix in a range of foods and beverages, including honey (Čajka et al. 2007), coffee (Ryan et al. 2004), cachaça (Cardeal et al. 2008), pepper (Cardeal et al. 2006), ginger (Shao et al. 2003), and grapes and wine (Perestrelo et al. 2010, Rocha et al. 2007, Ryan et al. 2005, Ryona et al. 2008, 2009, 2010, Schmarr et al. 2010). The majority of these studies have used the method for targeted analysis where analytes are selected prior to analysis, such as ethyl carbamate (Perestrelo et al. 2010), methoxypyrazines (Ryan et al. 2005, Ryona et al. 2008, 2009, 201,) and aroma-active aldehydes (Schmarr 2008b). Only a few publications have used the technique for nontargeted volatile profiling of grapes and wines (Robinson et al. 2011a, 2011b, 2011c, Rocha et al. 2007, Schmarr et al. 2010, Vestner et al. 2011, Weldegergis et al. 2011a, 2011b). In nontargeted profiling, the overall MS fingerprint, or pattern, is used to distinguish among samples and chromatographic peaks need not be identified before (or after) the analysis. The improved resolution of $\mathrm{GC} \times \mathrm{GC}$ separations enhances the ability to obtain detailed fingerprints of complex samples since individual peaks are more likely to correspond to unique analytes, ultimately aiding in compound identification.

In a recent example, $\mathrm{GC} \times \mathrm{GC}$ was used to analyze monoterpenes in grapes and 56 monoterpenes were identified in the Fernão-Pires variety, of which 20 were reported for the first time in grapes (Rocha et al 2007). This highlighted the advantage that structured chromatographic separation can provide for compound classification and confirmation of compound identity. There continues to be new aroma compound discoveries in the grape and wine research field, including (E)-1-(2,3,6-trimethylphenyl)buta-1,3-diene (TPB) (Cox et al. 2005) and 3,4,5,6,7,8-hexahydro-3,8-dimethyl-5-(1-methylethenyl)azulene-1(2H)-one, or (-)-rotundone (Wood et al. 2008). Therefore, it is anticipated that $\mathrm{GC} \times \mathrm{GC}$ will provide significant advantages in the identification of new and novel compounds, which were previously unresolved using traditional one-dimensional chromatography. Finally, GC $\times \mathrm{GC}$ TOF-MS results are highly data intensive, and improved methods for peak alignment, deconvolution, and compound identification for large data sets are needed (Yang et al. 2013).

\section{Analysis of Glycoconjugates}

Because glycosidically bound aroma compounds are nonvolatile, the most common method of glycoconjugate analysis has been to measure the aglycone and/or the sugar moiety separately following controlled acid or enzyme hydrolysis (Williams 1993, Günata et al. 1993). In these studies, GC-MS is most commonly used to analyze, identify, and quantify the aglycones, such as terpenes, benzenoids, and aliphatic residues. The released sugar moieties, such as mono- or di-glucoside, arabinofuranoside, and rhamnopyranoside (Williams 1993), can be analyzed by HPLC or other chromatographic approaches.

There are a limited number of studies where the glycoconjugates are measured directly. Typically in these studies, the glycoconjugates are initially isolated and fractionated from the matrix using low- (or atmospheric) pressure liquid chromatography, HPLC, counter-current chromatography (CCC), and/or supercritical fluid extraction (SFE) (Strauss et al. 1987, Winterhalter et al. 1990, Bonnländer et al. 1998, Palma et al. 2000). The isolated glycoconjugate fraction is then analyzed directly by fast atom bombardment tandem MS (FAB-MS) (Marinos et al. 1994), HPLC-MS and/or MS/MS (Hayasaka et al. 2010a), and matrix-assisted laser desorption/ionization 
time-of-flight (MALDI-TOF) MS (Nasi et al. 2008). There are opportunities to use other analytical techniques, including high-resolution TOF-MS and FT-ICR MS. However, these techniques have not yet been used for the analysis of glycoconjugated aroma compounds.

A rapid form of glycoconjugate analysis in wine is possible through application of the so-called glycosyl-glucose assay (Williams et al. 1995). In this approach, the glycosides are hydrolyzed and the released glucose and fructose are measured enzymatically. The assay is rapid, accurate, and precise (Williams et al. 1995) and has been used for determination of aroma potential in grapes (Zoecklein et al. 1998, Escalona et al. 1999). The determination of glycosyl-glucose provides a measure of the amount of conjugated compounds present but provides no qualitative information about the speciation of either the sugars or the aroma compounds. In addition, since grapes also contain significant amounts of glycosidically bound polyphenols (e.g., malvidin-3-glucoside and rutin), the glycosyl-glucose assay will also measure sugars released by hydrolysis of these compounds. Therefore, sample pretreatment with polyvinylpolypyrrolidone (PVPP) may be used to remove the phenolic glycosides prior to analysis of aroma potential (Zoecklein et al. 2000).

\section{Sample Preservation and Preparation}

Sample preparation is a critical step in any chemical analysis, and the information obtained from chromatographic or MS analyses is highly dependent on the sample preparation method chosen. Techniques that effectively isolate volatile aroma compounds or their precursors from nonvolatile matrix components are typically of greatest interest for analysis of flavor compounds and will be the main focus of this discussion. At any stage of sample preparation it is important to preserve the compounds of interest; control of temperature, oxygen, and enzyme activity are keys to reducing formation of oxidative or other chemical artifacts. As noted in Part 1 of this review, many aroma compounds are present as glycoconjugates (or cysteinyl- and glutathionyl conjugates), and preservation of conjugated compounds may be important in determining aroma potential. Therefore, cold storage prior to analysis is preferable to minimize the acid hydrolysis of glycoconjugates that can slowly occur at juice $\mathrm{pH}$ and ambient temperature (Skouroumounis and Sefton 2000). Further, enzyme hydrolysis by most native enzymes is inhibited in juice environments (Günata et al. 1993), but enzyme inhibitors can be added to the extract as a precaution (Razungles et al. 1993).

Liquid extraction. In many studies, volatile and glycosylated aroma precursors are isolated from plant extracts, fruit juice, dealcoholized wine, and other liquid media either by selective retention on Amberlite XAD resins (typically XAD2) (Günata et al. 1985), on $C_{18}$ reversed-phase silica adsorbent (Williams et al. 1982), or by simple liquid/liquid extraction. These techniques allow the isolation of aroma and aroma precursor compounds free of sugars and organic acids (Günata et al. 1985). The compounds of interest are selectively eluted from the resins/adsorbents or extracted with organic solvents of varied polarity (Mateo et al. 1997, Guyot-Declerck et al.
2000). The organic eluates are collected, dried, and concentrated for analysis. These are simple and effective methods. However, there is little scope for automation, limiting sample throughput, and the methods involve contact with potentially hazardous organic solvents, which must be disposed of.

There has been recent interest in liquid microextraction techniques to minimize use of organic solvents. These use very small amounts of solvents to extract analytes and include (1) single-drop microextraction (extraction solvent flows past a drop of liquid sample); (2) membrane extraction (sample and solvent are separated by a porous polymeric membrane and solutes partition into the organic phase based on their partition coefficients); and (3) dispersive liquid-liquid microextraction (extracting solvent is dispersed as fine droplets in the liquid sample; analytes partition into the solvent which is then separated by density from the liquid sample). Principles and applications of these techniques for wine analysis have been described (Kloskowski et al. 2007, Pena-Pereira et al. 2009, Ebeler 2012). In particular, dispersive liquid-liquid microextraction has been used for analysis of grape and wine flavor compounds, including polyfunctional thiol aroma compounds, halophenols, geosmin, and methyl isoborneol (Campillo et al. 2010, Fontana et al. 2010, Jofré et al. 2010, Pizarro et al. 2010, 2011a, Cortada et al. 2011). The methods are rapid and sensitive; however, matrix interferences can be significant, particularly with red wines (Montes et al. 2009).

Static and dynamic HS extraction. The greatest advantage of static and dynamic HS extraction methodologies is that they directly sample the volatile composition of the sample headspace, which can then be directly related to the aroma of the sample. Static HS extraction involves sampling the headspace, at equilibrium, typically using a syringe and injecting the headspace gas directly into the GC inlet, often with cryofocusing to sharpen the early eluting peaks. Dynamic HS extraction involves flushing the headspace of the sample vial with inert gas over a defined time period. The liberated volatiles are usually captured in a cold trap or adsorbent such as Tenax prior to injection onto a GC (Rosillo et al. 1999). Static HS extraction has been used effectively to determine partition coefficients of analytes in aqueous ethanol solutions (Conner et al. 1994, 1998, Athès et al. 2004). These methods are simple but have poor reproducibility, are biased toward extraction of highly volatile and semivolatile compounds, have limitations in detecting trace analytes, and as a result are often unrepresentative of the sample composition (Ortega-Heras et al. 2002). Static and dynamic HS extractions have been shown to be less sensitive and less selective methods for headspace analysis when compared to SPME (Kataoka et al. 2000). However, in some cases, particularly for highly volatile compounds, static HS methods can be highly sensitive, as when detection limits of 0.1 to $3 \mathrm{ug} / \mathrm{L}$ for low molecular weight sulfur compounds in wines were obtained (e.g., $\mathrm{H}_{2} \mathrm{~S}$ and DMS) (Rauhut et al. 1998), similar to those reported using other approaches, including HS-SPMEGC (Herszage and Ebeler 2011).

HS-SPME. Solid-phase microextraction (SPME) has been increasingly used in volatile flavor analysis since its 
introduction in the 1990s (Arthur and Pawliszyn 1990, Arthur et al. 1992, Zhang and Pawliszyn 1993, Pan et al. 1995, Steffen and Pawliszyn 1996). The primary advantage of this technique is that it combines analyte extraction and preconcentration in a single step, without significant sample preparation. Sampling with the SPME fiber can occur either from the headspace (HS-SPME) or from the liquid phase (direct immersion or DI-SPME), although most applications for analysis of aroma volatiles sample from the headspace. A number of grape and wine profiling studies have used HSSPME to better understand the role of various compounds in differentiating varieties, regions, and wine vintage (Marengo et al. 2002, Câmara et al. 2007, Setkova et al. 2007b, Robinson et al. 2011c), and the technique has been repeatedly documented as a sensitive, reproducible, automated method for preconcentration of wine volatiles prior to analysis (Howard et al. 2005, Câmara et al. 2006, Setkova et al. 2007a). Various parameters are routinely optimized in the development of HS-SPME techniques for the analysis in wine of ethyl esters, acetates, acids, and alcohols (Siebert et al. 2005), monoterpenes and norisoprenoids (Câmara et al. 2006), methoxypyrazines (Hartmann et al. 2002, Ryona et al. 2009), thiols, sulfides, and disulfides (Mestres et al. 1999a, 1999b), and furfural derivatives, phenolic aldehydes, volatile phenols, and oak lactones (Carrillo et al. 2006). Most methods described within the literature explore parameters such as fiber type, sample temperature, salt concentration, agitation speed, and extraction time as part of method development and optimization (Sala et al. 2000, Rocha et al. 2001, Silva Ferreira and Guedes de Pinho 2003, Howard et al. 2005, Câmara et al. 2006, Carrillo et al. 2006, Setkova et al. 2007a, Robinson et al. 2011b). This agrees with a recently published protocol for SPME method development (Risticevic et al. 2010a). A recent review provides an extensive summary of the applications of SPME for grape and wine analysis (Jelen et al. 2012). The following sections address the relevant parameters that should be considered for wine sample preparation for HSSPME volatile analyses.

SPME fiber type. SPME fibers are coated with a variety of single or mixed polymers that vary in polarity, thickness, and length. The mechanisms of extraction differ: single and/ or liquid phases absorb analytes into the entire fiber coating and mixed and/or solid phases adsorb analytes to the surface of the fiber coating. This has implications with respect to sensitivity and time to reach extraction equilibrium (Risticevic et al. 2010a) and to influence the potential for matrix components to compete with analytes for fiber adsorption/ binding sites, as can occur with carboxen-based polymers (Murray 2001). The polarity of the fiber coating also allows the user to target specific compounds based on their affinity for the fiber, that is, based on the principle that "like dissolves like" (Risticevic et al. 2010a). Common SPME sorptive phases or mixtures of phases that are used for the analysis of volatile compounds in wine include polydimethylsiloxane (PDMS), polyacrylate (PA), divinylbenzene (DVB), and carboxen (CAR) (Rocha et al. 2001, Howard et al. 2005, Setkova et al. 2007a, Risticevic et al. 2010a).
Sample temperature. Increasing the sample temperature during extraction can increase analyte partitioning into the headspace and thus increase the amount extracted improving the sensitivity of the HS-SPME method (Risticevic et al. 2010a). However, desorption from the fiber may also increase at higher temperatures, decreasing the overall analyte partitioning into the SPME fiber phase (Fischer and Fischer 1997). In addition, it has been observed that elevated extraction temperatures can modify monoterpenes (Varming et al. 2004, 2006, Perez-Cacho and Rouseff 2008), esters, and acetates (Marais and Pool 1980, Ramey and Ough 1980, PérezCoello et al. 2003) and release volatiles from glycosylated aroma precursors (Silva Ferreira and Guedes de Pinho 2004). While no studies to date have thoroughly addressed the role of temperature in modifying volatiles in a wine sample during SPME sampling at elevated temperatures, it has been noted that different volatile profiles were observed from honey samples conditioned at temperatures $>60^{\circ} \mathrm{C}$, compared to those kept at room temperature (Čajka et al. 2007). It is possible that similar results could occur if wine or grape juice samples were also heated. This aspect of HS-SPME method development should be more fully studied. However, when trying to relate HS-SPME results to data obtained by sensory panels, it would seem sensible to use temperatures either between 20 and $25^{\circ} \mathrm{C}$, corresponding to room temperature tasting conditions, or between 30 and $40^{\circ} \mathrm{C}$, simulating mouth temperatures and aroma release in the mouth.

Salting-out. The salting-out, or Setschenow effect, describes how a nonelectrolyte, in this case an organic volatile compound, decreases in solubility following the addition of an electrolyte such as sodium chloride to the solution (Mazo 2006). The addition of salt to wine samples can increase the partitioning of aroma compounds into the headspace and increase their extraction/partitioning onto the SPME fiber. Given that the Setschenow effect is related to the preferential association of electrolytes with the solvent with respect to the nonelectrolyte solute, it can be assumed that once the electrolyte reaches saturation the further addition of electrolyte will not cause a greater effect. By extrapolating from the raw data presented in one study (Farelo et al. 2004), it is observed that in a $13 \%$ ethanol solution at $30^{\circ} \mathrm{C}$ sodium chloride reaches saturation at $\sim 274 \mathrm{~g} / \mathrm{L}$. Dry white and red table wines are characterized by an alcohol content ranging from 10 to $15 \%$ ethanol by volume, where sodium chloride is saturated at 292 and $262 \mathrm{~g} / \mathrm{L}$, respectively. Thus, sodium chloride concentrations between 250 and $300 \mathrm{~g} / \mathrm{L}$ will generally accommodate the alcohol content of wine products at or around ambient temperatures. Interestingly, this falls within the frequently reported range of 100 to $350 \mathrm{~g} / \mathrm{L}$ of added salt determined experimentally for optimal extractions of wine volatiles by HS-SPME (De La Calle García et al. 1998, Rocha et al. 2001, Azenha and Vasconcelos 2002, Rodríguez-Bencomo et al. 2002, Castro Mejías et al. 2003, Demyttenaere et al. 2003, Castro et al. 2004, Siebert et al. 2005, Câmara et al. 2006, Setkova et al. 2007a, Robinson et al. 2011c).

Sample agitation. Mechanical agitation plays an important role in accelerating mass transfer of molecules from the liquid 
into the headspace. Agitation increases mixing of molecules within the liquid, creating a relatively homogenous mixture at any point in time (Zhang and Pawliszyn 1993). Agitation also increases the rotational velocity of the liquid, forcing the liquid toward the sides of the container and thus increasing the gas-liquid interface surface area. The effects of sample agitation on HS-SPME analyses have been reviewed (Zhang and Pawliszyn 1993). The rate of analyte diffusion (i.e., diffusive flux) from the liquid to the headspace is described by Fick's first law (Equation 1):

$$
J=-D \frac{\Delta \phi}{\Delta x}
$$

where $J$ is the diffusive flux, $D$ is the diffusion coefficient, $\phi$ is the concentration, and $x$ is the position. The diffusive flux of a compound is dependent on the concentration gradient and is directly proportional to the area of the gas-liquid interface. As agitation speeds increase, the surface area is maximized such that it is approximately equal to the ratio of the internal circumference of the vessel to the height (Equation 2):

$$
\Delta A \approx \frac{H}{0.5 r}
$$

where $\Delta A$ is the change in surface area, $H$ is the height of the vessel, and $r$ is the internal radius of the vial. As a consequence, the greater the agitation speed, the greater the effective surface area for the transfer of volatiles across the gas-liquid interface. In addition, a higher level of agitation will result in a constant concentration of volatiles at the gasliquid interface due to continuous effective mixing.

Extraction time. The SPME extraction time chosen will depend on the method objectives. If sampling of only volatiles in the headspace is desired, without influencing the partitioning of the volatiles from the liquid phase into the headspace, then short sampling times are used ( $\sim 1$ to $5 \mathrm{~min}$ ) (Lloyd et al. 2011). Sampling under these conditions is similar to a static HS extraction (Jung and Ebeler 2003). However, in most cases, SPME extraction is optimized to maximize extraction from the liquid phase and sampling may be long enough to establish an equilibrium partitioning of the volatile analytes among the liquid phase, vapor phase, and fiber phase.

When choosing and optimizing extraction times, there are three scenarios that are generally considered (Risticevic et al. 2010a). First, high-throughput methods require that the extraction time be proportional to the separation and detection time requirements: for example, if the user intends to complete a chromatographic run in 5 minutes (Setkova et al. 2007a), then the extraction time is only likely to be as long or slightly longer than 5 minutes (taking into account cool-down time). Short extraction times are usually pre-equilibrium conditions and are subject to errors associated with slight variations in extraction times; thus, automation control is essential for maximum reproducibility of the analysis (Risticevic et al. 2010a). Second, high-sensitivity methods may require longer extraction times to establish equilibrium between the SPME fiber and the headspace. In some instances, HS-SPME extraction times of 120 minutes have been used for wine volatile analysis to maximize extraction efficiency (Câmara et al. 2006). Third, good reproducibility is paramount in quantitative and semiquantitative analysis; thus to minimize variability in the amount of analyte extracted, equilibrium conditions should be used since these reduce timing-related errors. The exception is when precise automation is available and the user can demonstrate that the errors incurred due to timing are minimal (Risticevic et al. 2010a).

The optimal extraction time is dependent on the chemical and physical properties of the analytes. Optimal extraction times for a given analyte can be estimated from Graham's law of diffusion (Equation 3):

$$
K_{m}=\frac{1}{2} \cdot m_{m} \cdot v_{m}^{2}
$$

where $K_{m}$ is the kinetic energy of the analyte molecule, $m_{m}$ is the mass of the molecule, and $v_{m}$ is the velocity of diffusion of the molecule. Assuming that the kinetic energy of any molecule is constant at any given temperature and pressure, Equation 3 can be simplified (Equation 4):

$$
v_{m} \propto \sqrt{\frac{1}{m_{m}}}
$$

This demonstrates that the diffusion of the molecule in the gaseous phase toward the SPME fiber is dependent on the molecular mass of the molecule. Consequently, it is expected that the analysis of higher molecular weight compounds would require a longer extraction time compared to low molecular weight compounds, which have faster diffusion rates in the headspace comparatively.

Thus, the optimum extraction time depends on the nature of the analysis and the analytes being measured. Highthroughput analysis necessitates shorter extraction times but may forego the benefits of increased sensitivity for particular compounds; longer extraction times will have a greater likelihood of the samples reaching equilibrium between the liquid, vapor, and fiber phases, which will result in greater sensitivity and improved precision.

Desorption conditions. After extraction, the SPME fiber is inserted into the heated GC inlet and the volatile analytes are desorbed and swept into the GC column by the carrier gas. Desorption time and temperatures should be selected to (1) rapidly desorb the analytes within the first $\sim 30$ seconds after injection; (2) quantitatively and completely transfer the analytes to the column, minimizing carry-over on the fiber; and (3) minimize any thermal reactions that may occur in the inlet. Artifact formation in the inlet has been observed in analysis of volatile sulfur compounds using SPME sample preparation (Lestremau et al. 2004). High inlet temperatures used for SPME desorption increased the oxidation of thiols; carboxen-based fibers also appeared to increase the extent of oxidation during desorption in the inlet, with the carboxen possibly acting as a catalyst (Lestremau et al. 2004). The formation of Maillard products following the immediate thermal desorption of a liquid SPME sample from strawberry and apple fruit has been documented (Verhoeven et al. 1997), and the study identified the importance of washing the SPME 
fiber prior to introduction in the inlet when conducting liquid SPME analysis of samples high in carbohydrates and/or amines.

Stir-bar sorptive extraction and HS sorptive extraction. Stir-bar sorptive extraction (SBSE), or Twister, was developed in 1999 (Baltussen et al. 1999) and works on the same basic principal as SPME where the analyte of interest partitions between the sample matrix and a polymeric extraction phase. However, rather than coating the extracting polymer on a short ( 1 to $2 \mathrm{~cm}$ ) narrow-diameter $(\sim 0.56$ to $0.64 \mathrm{~mm})$ fused silica needle, the polymer is coated onto the outside of a glass magnetic stir bar (10 to $20 \mathrm{~mm}$ length). With SBSE, sampling occurs by placing the stir bar directly into the liquid phase for extraction, while HS-sorptive extraction (HSSE) samples from the headspace/vapor phase. The major advantage of SBSE and HSSE over SPME is that the stir bar is coated with 25 to $125 \mu \mathrm{L}$ of sorptive phase (PDMS) compared with only $\sim 0.5 \mu \mathrm{L}$ of sorptive phase on a SPME fiber; the increased mass of the SBSE sorptive phase allows for a substantial increase in sensitivity (Lancas et al. 2009). However, the SBSE/HSSE coatings are currently limited with respect to sorptive phase types: PDMS and PDMS/ethylene glycol copolymer are the only commercially available phases. In addition, specialized thermal desorption and cryofocusing inlets and sampling stations are required on the GC-MS instruments. An early application of SBSE for wine analysis was for the sensitive measurement of 2,4,6-trichloroanisole (TCA) contamination, and more recent applications for grape and wine flavor analysis have recently been reviewed (Sponholz et al. 2001, Jelen et al. 2012).

\section{Quantification of Volatiles}

All sample preparation techniques will result in some selectivity and/or analyte losses during sample extraction/ isolation (Flath 1977, Jennings and Filsoof 1977, Risticevic et al. 2010a). In addition, GC detector responses are often dependent on analyte chemical structure. While GC-MS detectors are often considered universal detectors responding to all chemical masses (within the defined mass range of the instrument), differences in analyte ionization and fragmentation efficiencies can result in different detector response ratios. For this reason, careful calibration is needed for accurate analyte quantification, depending on experimental objectives.

General reviews of external standard, internal standard, and standard addition calibration methods are widely available in most analytical chemistry textbooks (e.g., Christian 2007, Harris 2003), and the choice of calibration method will depend on the analyte, the matrix, the analysis throughput needs, and the amount of sample available. Internal standards are widely used for correcting for matrix effects, sample preparation losses, and/or injection variability. Surrogate internal standards are added at the beginning of the sample preparation or extraction steps to monitor the entire analytical process. Using a surrogate internal standard, average losses of $\sim 50 \%$ were observed during preparation of samples for HSSPME GC-MS profiling of volatiles in Cabernet Sauvignon skins; by monitoring these losses with the internal standard, analyte recoveries could be estimated for accurate quantification (Canuti et al. 2009). Internal standards may also be added immediately before injection/analysis to account for injection variability or variability in HS-SPME extraction. A HS-SPME approach where the internal standard is loaded onto the fiber coating before sample extraction (rather than adding the internal standard separately to each sample) has recently been proposed for the high throughput and reproducible analysis of volatile, semivolatile, and nonvolatile analytes (Risticevic et al. 2010b).

Internal standards labeled with stable isotopes (e.g., ${ }^{2} \mathrm{H}$, ${ }^{13} \mathrm{C}$, and ${ }^{15} \mathrm{~N}$ ) that match the analyte/s of interest are widely used for accurate GC-MS quantification of aroma volatiles in foods and beverages, including grapes and wines (Polášková et al. 2008, Ebeler 2012, Schieberle and Molyneux 2012). Multiple internal standards are often used, as demonstrated in a recent study where 29 stable isotope-matched internal standards were used to accurately quantify 31 different wine components with HS-SPME GC-MS analysis (Siebert et al. 2005). Availability of stable isotope standards is often limited, however, and chemical synthesis is required if commercial standards are not available. A recent approach used a single uniformly labeled precursor (e.g., [U- $\left.{ }^{13} \mathrm{C}\right]-\alpha$-linolenic acid) to produce a suite of labeled products that were subsequently characterized using reverse-isotope dilution procedures and then used for stable isotope dilution analysis (SIDA) in volatile profiling studies (Gomez-Cortez et al. 2012). Such an approach may be significantly more time and cost effective than synthesis of multiple labeled internal standards but has not yet been applied to analysis of grape and wine volatiles.

\section{GC-Olfactometry}

GC-olfactometry (GC-O), originally proposed in 1964 (Fuller et al. 1964), uses the human nose as a detector for the compounds eluting from a chromatographic column (Acree et al. 1984). The method has been promoted as a useful tool in determining the sensory character of some flavor compounds (Deibler et al. 1999, Kotseridis and Baumes 2000, Aznar et al. 2001, Grosch 2001, Friedrich and Acree 2002, Plutowska and Wardencki 2008). In addition, compounds with the most impact on the overall aroma can be defined through sequential dilutions of an aroma extract - those compounds having the greatest impact on the aroma are those that still can be detected sensorially by GC-O after numerous serial dilutions. Using this process, a sample containing hundreds of aroma compounds can typically be reduced to a subset of $\sim 10$ to 20 compounds that are most important to the overall aroma of the sample (Grosch 2001).

Although useful in characterizing aroma compounds and for initial investigations, GC-O may not allow for the extrapolation of the sensory contribution of an aroma compound to the actual wine sample (Barbe et al. 2008). This can be attributed to the fact that $\mathrm{GC}-\mathrm{O}$ analysis essentially evaluates the aroma of the compounds individually and separate from the sample matrix. GC-O does not take into account the interaction effects that occur when aroma compound interact with the nonvolatile matrix (Pineau et al. 2007, Robinson et 
al. 2009, Sáenz-Navajas et al. 2010, 2012) and with other volatile compounds (Atanasova et al. 2005b, Escudero et al. 2007, Pineau et al. 2009). As discussed later, these interactions may result in variations in the sensory character of the mixture due to enhancement and suppression effects. GC-O also tends to focus on potent aroma compounds, which chromatograph well at low concentrations, while abundant compounds tend to overload the chromatographic column, resulting in broad peaks that elute in the effluent over a long period of time and presenting only a fraction of the compound to the operator to smell.

A recent modification of $\mathrm{GC}-\mathrm{O}$ allows individual peaks or groups of peaks to be selectively recombined as they elute off the column and smelled as a mixture (Johnson et al. 2012). The GC-recomposition olfactometry (GC-R) technique allows the creation of aroma reconstitutions without the need for chemical standards or reductive aroma models. This technique provides a holistic approach for understanding the aroma of complex mixtures and allows for additive, masking, and synergistic effects of mixtures to be readily evaluated. When applied to wine samples, this approach may make it possible to more fully characterize grape and wine varietal characters, which are the result of interactions of many aroma compounds acting together to produce the overall sensory perception.

Odor activity values (OAVs) are also widely used for selecting compounds in a mixture that have the most impact on perceived aroma (Grosch 2001). In this approach, the concentration of all aroma volatiles in the sample is determined and then combined with sensory threshold information determined separately using the pure chemicals. The OAV is then determined as a ratio of the measured analyte concentration in the sample to the analyte sensory threshold. Those compounds with high OAVs would be expected to most directly impact the overall aroma of the sample (Grosch 2001). This technique requires that analytes be accurately quantified and that pure compounds be available to determine sensory thresholds, which, in many cases, may not be possible. In addition, this approach does not account for the complex interactions that occur in perception of mixtures. Since sensory thresholds are determined statistically using a large number of panelists, they are dependent on a large number of variables, including the sample matrix, and as such they may not reflect the range of concentrations that may actually be perceived in a given food matrix by an individual. Finally, the relationship between perceived intensity and concentration at suprathreshold concentrations cannot be predicted from the threshold concentration (i.e., the slope of a plot of perceived intensity vs. concentration is different for different compounds). Because of these limitations, OAVs are not always good indicators of the contribution of individual odorants to the perceived intensity of a mixture (Audouin et al. 2001), as further demonstrated with the white wine variety Maccabeo using reconstitution studies with a dearomatized white wine matrix and pure aroma compounds (Escudero et al. 2004). Selected compounds such as fusel alcohols, acids, and esters, even when present at concentrations above their sensory thresholds, did not have a significant impact on the overall wine aroma. On the other hand, a group of compounds with odor activities less than one were important to reconstructing the aroma of the original Maccabeo wine.

The analytical approaches described in the above sections are focused on fully characterizing the chemical composition of grapes and wines. GC-O approaches attempt to link composition directly to the sensory impact of individual compounds. However, as discussed above with GC-recomposition olfactometry analysis, holistic measurements of sensory perception are also necessary to fully characterize wine flavor. Such approaches for sensory evaluation of wine are discussed in the following section.

\section{Sensory Evaluation of Wine}

Sensory evaluation stems from the experimental psychology field of psychophysics, which explores how human responses are elicited by chemical and physical stimuli. Early work in this field by researchers including Ernst Weber and Gustav Fechner investigated the mathematical relationship between the physical and perceptual magnitude of stimuli and is still the subject of much cognitive research (Dehaene 2003). Where psychophysics might focus experimental research on understanding how humans respond to stimuli, sensory evaluation focuses on using human subjects to explore the sensory properties of stimuli. Sensory evaluation has been defined as a scientific method used to evoke, measure, analyze, and interpret those responses to products as perceived through the senses of sight, smell, touch, taste, and hearing (Lawless and Heymann 2010). Sensory evaluation in the food, beverage, and fragrance industries was historically conducted by product experts such as the cheesemaker, winemaker, or perfumer, who had training and extensive knowledge of how raw materials and processing affected the finished product quality (Sidel and Stone 1993). Although these product experts are still commonly used in industry today, the use of specialized sensory panels for conducting discriminative, descriptive, and affective evaluations of products has many more advantages. It is generally recognized that the judgments of a panel are generally more reliable than the judgments of an individual, there is less potential risk that the single expert might be ill/ retire/die or otherwise be unavailable to make decisions, and, most importantly, the opinions of the expert may or may not reflect what consumers want in a product (Sidel and Stone 1993).

Several types of sensory tests are possible, including discrimination, descriptive, and consumer. Discrimination tests determine whether two products are perceptibly different from one another, for example, due to a modification in the production process or the identification of a defect. These tests are commonly fast and easy to conduct and require little training. However, they provide little additional detail about why the differences exist or the relative impact of the difference (Peryam and Swartz 1950, Lawless and Heymann 2010). Descriptive tests are used to obtain a more detailed description of the sensory attributes of a product. These tests assist in identifying which attributes vary due to a modification to 
the product or to compare attributes between/among products. Descriptive tests typically require additional time and panel training compared to difference tests (Murray et al. 2001, Lawless and Heymann 2010). Consumer (hedonic) tests are used to determine if a consumer likes a product, prefers it to another product, or finds the product acceptable based on its sensory characteristics. These tests are different from market research where the extrinsic factors that can affect wine choice are also considered, such as brand, region, price, and awards (Lockshin et al. 2006, Lawless and Heymann 2010).

Wine is a highly diversified food product made from numerous grape varieties, grown in a diverse range of environments worldwide, and produced using a multitude of permutations in viticultural management and winemaking techniques that have been developed over the course of centuries. As such, the sensory characteristics of wines are highly varied. Use of standardized terminology can aid in the communication of sensory attributes of wine products among winemakers, marketers, consumers, and researchers (Noble et al. 1984, 1987, Gawel 1998, Gawel et al. 2000). However, standardized terminology is not always used by winemakers, wine writers, and consumers, who frequently use everyday language to infer relationships between the wine product and the sensory properties of other common food products and smells. This was demonstrated in a study of vegetal aromas in Cabernet Sauvignon wines using expert winemakers and trained sensory panelists (Preston et al. 2008). Experts used a variety of terms to group and describe vegetal characters in the wines, and in some cases vegetal and sulfur attributes were often grouped similarly. However, trained panelists reliably distinguished between related vegetal terms such as a fresh, bell pepper-like aroma, a cooked vegetal aroma (a mixture of canned potatoes corn, green been, and asparagus), a green/ black olive aroma, and a eucalyptus aroma. Each of these aroma attributes would arise from different chemical components. Therefore, in order to minimize or optimize specific aroma characteristics in a wine, precise and well-defined terminology for sensory attributes, as is obtained with sensory descriptive analyses, is needed when communicating about wine sensory properties.

Descriptive analysis of wine and linking sensory and chemical data. To quote a succinct summary of the importance of descriptive sensory analyses, "Without sensory evaluation, even precise information about the volatile composition in the nasal passages cannot predict the flavor of the system as perceived by humans" (Noble and Ebeler 2002). Descriptive sensory analysis is one of the most powerful tools for conducting product comparisons and for determining relationships between sensory properties of foods and beverages and their composition or consumer liking (Murray et al. 2001, Lawless and Heymann 2010). There are a number of different methods for conducting descriptive analysis, including the flavor profile method, texture profile method, Quantitative Descriptive Analysis ${ }^{\mathrm{TM}}$, the Spectrum ${ }^{\mathrm{TM}}$ method, quantitative flavor profiling, and free-choice profiling, and their comparable advantages and disadvantages have been previously discussed in a review of the field (Murray et al. 2001). Descrip- tive sensory analysis has been used extensively in the wine industry over the last 30 years following pioneering work conducted by Ann Noble and coworkers at the University of California, Davis, in the late 1970s and early 1980s (Arnold and Noble 1979, Schmidt and Noble 1983, Aiken and Noble 1984, Heymann and Noble 1987, Noble and Shannon 1987).

Numerous studies have used descriptive sensory analysis to explore differences in the sensory characteristics of single variety wines, including Cabernet Sauvignon (Heymann and Noble 1987), Chardonnay (Arrhenius et al. 1996), Pinot noir (Guinard and Cliff 1987), and Zinfandel (Noble and Shannon 1987) from California, Seyval blanc from Missouri (Andrews et al. 1990), Cabernet franc from the Niagara region (Hakimi Rezaei and Reynolds 2010), Cabernet Sauvignon from Australia (Robinson et al. 2011a), Riesling from Germany (Fischer et al. 1999), Malbec from Argentina (Goldner and Zamora 2007), Albariño from Spain (Vilanova and Vilariño 2006), Touriga Nacional and Tinta Roriz from Portugal (Falqué et al. 2004), and Sauvignon blanc from New Zealand and other countries (Lund et al. 2009). In addition, numerous studies have predominantly used descriptive sensory analysis to explore the sensory impacts of various viticultural and enological treatments (Lesschaeve 2007, Robinson et al. 2011b), such as the influence of oak (Francis et al. 1992, Reynolds et al. 2001, Cano-López et al. 2008), fermentation with different yeast strains and temperatures (Eglinton et al. 2000, Soden et al. 2000), wine storage temperature conditions (Francis et al. 1994, De La Presa-Owens and Noble 1997, Robinson et al. 2010, Hopfer et al. 2012b, 2013), closure types (Godden et al. 2001, Skouroumounis et al. 2005a, 2005b, Hopfer et al. 2012b, 2013), grapevine diseases including Botrytis cinerea and Uncinula necator (powdery mildew) (Stummer et al. 2003, 2005, Sivertsen et al. 2005), and grapevine water status, crop yield, and canopy management (Reynolds et al. 1996, 2013, Chapman et al. 2004, 2005).

Although many studies have explored the sensory differences among imposed treatments, there is much current interest in exploring the relationships between these sensory differences and wine composition and/or the sensory aspects of wine associated with consumer preferences (Francis and Newton 2005, Lesschaeve 2007). Recent examples include identification of sensory attributes that drive consumer and expert acceptance of Shiraz and Cabernet Sauvignon wines (Lattey et al. 2010), assessment of the relationship between sensory and chemical data for oak-derived compounds found in French and Spanish wines (Prida and Chatonnet 2010), modeling of wine mouthfeel attributes using metabolomic data (Skogerson et al. 2009), comparisons between vine vigor status with tannin and sensory data (Cortell et al. 2008), assessment of the relationships between red wine textural characteristics and the chemical composition of Shiraz wines (Gawel et al. 2007), comparisons of volatile components of sweet Fiano wines and sensory data (Genovese et al. 2007), and comparisons between volatile compositional data and sensory data of Chardonnay, Cabernet Sauvignon, Malbec, and Sauvignon blanc wines made in different styles and/or from different regions (Lee and Noble 2006, Robinson et al. 
2011a, 2011b, Benkwitz et al. 2012, Hjelmeland et al. 2013, King et al. 2014). Future work may also consider aspects of wine and food interactions, given that an understanding of how people enjoy pairing wine with food combinations is commonly discussed in the popular literature (MadrigalGalan and Heymann 2006).

In a recent study both sensory descriptive analysis and chemical analysis were used to understand the influences of blending on chemical and sensory profiles of Cabernet Sauvignon, Merlot, and Cabernet franc monovarietal wines and their blends (Hopfer et al. 2012a). Blending resulted in changes to both sensory and chemical characteristics relative to the original monovarietal wines. The measured chemical composition reflected the average composition of each monovarietal wine in the blend. However, the sensory profiles exhibited examples of suppressing or amplifying effects, and the overall sensory profile was not a simple average of the sensory profile of the monovarietal base wines. Interestingly, similar sensory profiles could be obtained with very different blending mixtures. This study demonstrates the value of using both sensory and chemical analyses to describe wine aroma and flavor, but also points to the difficulties in fully linking compositional information to sensory properties due to complex aroma interactions. These aroma interactions are further discussed below.

In all cases, descriptive sensory analysis produces multivariate data in relation to a single sample set. In the above examples, multivariate statistical techniques have also been critical in exploring relationships between descriptive sensory data and compositional and/or consumer sensory data, such as multivariate analysis of variance (MANOVA), principal component analysis (PCA), canonical variate analysis (CVA), generalized Procrustes analysis (GPA), and partial least squares (PLS) regression. In general, the use of multivariate statistics for relating sensory and chemical data has been well described (Noble and Ebeler 2002, Lawless and Heymann 2010, Naes et al. 2011).

There is still need for improved methods for handling the large data sets involved in correlating analytical and sensory data. Standard workflows, particularly for analysis of chromatographic data, are time-consuming and involve many steps where automated data processing is still limited, as discussed previously. In addition, many of the statistical approaches currently used have limitations when the number of samples or treatments is small with respect to the number of variables (as frequently happens with hyphenated GC data such as $\mathrm{GC} \times \mathrm{GC}$ and high-resolution MS where hundreds of peaks may be present in a sample). Further, relationships among analyte concentrations, sensory responses, and treatment variables may not be linear, making it difficult to interpret results from statistical approaches based on linear relationships. Finally, in cases where predictive models are developed (e.g., PLS analysis relating analyte concentrations to sensory attribute intensities), methods of cross-validation and model testing must be clearly defined and the variability in responses observed within the training sets must represent the variability in the samples tested. An excellent overview of these issues has recently been presented (Smilde et al. 2013). An understanding of these limitations and new approaches for analysis of complex multivariate data sets may provide new opportunities for linking chemical and sensory data to fully understand the flavor of complex chemical mixtures.

Interaction effects on wine flavor. As previously discussed, much wine sensory research has focused on correlating descriptive sensory and quantitative analytical data in order to successfully identify odor compounds that contribute to the overall aroma perception of wine (Guth 1997a, 1997b, 1998, López et al. 1999, 2003, Kotseridis and Baumes 2000, Ferreira et al. 2001, 2002, Lee and Noble 2003, Escudero et al. 2004, Campo et al. 2005, Bailly et al. 2006, Benkwitz et al. 2012). The use of sensory evaluation to elucidate the impact of complex aroma compound interactions, including masking and enhancing effects, is likely to improve our understanding of the perceived aroma of wine (Atanasova et al. 2005a). For example, using descriptive analysis, it has been shown that fruity aromas in wines can significantly mask vegetal characters in the wines (Hein et al. 2009). Similarly, at low concentrations, $\beta$-damascenone has the ability to mask the herbaceous aroma associated with 3-isobutyl2-methoxypyrazine (Pineau et al. 2007) while enhancing the berry fruit aromas in red wines (Escudero et al. 2007, Pineau et al. 2007). As noted in the above section, the aromas of wine blends exhibited suppressive and amplifying effects when the intensity of specific aroma attributes of the blends was compared to the original aroma of the monovarietal wines (Hopfer et al. 2012a). These results indicate that aroma interactions in the complex wine blend mixtures can impact the overall aroma in a nonadditive manner (Hopfer et al. 2012a).

The matrix components can also impact aroma volatility, release, and perception. Recent sensory research has shown that ethanol suppresses the fruity notes in model wine solutions (Grosch 2001, Escudero et al. 2007, Le Berre et al. 2007, King et al. 2013) due to the increased solubility of the volatiles when ethanol is present (Le Berre et al. 2007, Robinson et al. 2009) and to the inhibition of volatile compound odor activity by ethanol (Grosch 2001). For example, $\beta$-damascenone is recognized universally as a potent wine aroma compound (Skouroumounis and Sefton 2002, Pineau et al. 2007, Sefton et al. 2011); however, its reported aroma threshold varies from 2 to $13 \mathrm{ng} / \mathrm{L}$ in water (Buttery et al. 1990, Czerny et al. 2008), to $50 \mathrm{ng} / \mathrm{L}$ (Guth 1997a) in 10\% aqueous ethanol, to $7000 \mathrm{ng} / \mathrm{L}$ in a red wine matrix (Pineau et al. 2007).

These results indicate that in addition to ethanol, other wine components also impact aroma perception, therefore understanding the factors that influence the release of volatiles from the complete wine matrix is of major importance to understanding wine aroma perception (Plug and Haring 1994). Several studies have shown that polyphenols, tannins, polysaccharides, and proteins can interact with aroma compounds and affect their volatility and release from solution (Dufour and Bayonove 1999a, 1999b, Voilley and Lubbers 1999, Jung et al. 2000, 2002, Jung and Ebeler 2003, Aronson and Ebeler 2004, Jones et al. 2008, Saenz-Navajas et al. 
2010, 2012, Villamor and Ross 2013). A recent study clearly demonstrated that nonvolatile tastants (e.g., polyphenols, tannins/high molecular weight components, glycerol, and organic acids) can significantly impact the perception of wine aroma compounds, enhancing the intensity of some attributes and decreasing the perceived intensity of others (Frank et al. 2011). The mechanisms for the interactions are not entirely clear but may be due to changes in solubility or noncovalent interactions/associations of the odorants with the solute components in solution (Connor et al. 1998, Jung et al. 2000, 2002).

The existence of interaction effects clearly supports the use of holistic approaches, such as descriptive analysis, in the sensory assessment of wine products where physical, chemical, and perceptual enhancement and suppression effects complicate the assessment of volatile components in isolation.

\section{Summary}

Advances in analytical, sensory, and statistical analysis have been critical for understanding the relationships between grape and wine composition and sensory perception. However, it is still not possible to fully predict aroma quality based on chemical composition alone, due, in part, to the potential presence of trace compounds that may be difficult to quantify and identify and to the complex interactions of aroma compounds with each other and with the wine matrix that impact aroma volatility, release, and perception. As outlined in this review, future discoveries will continue to be driven by development of improved and high-throughput analytical methods that will allow monitoring of a large number of volatiles, including those present at low concentrations. Sensory and statistical approaches that allow for handling of large multivariate data sets are also needed. Ultimately, multidisciplinary studies using genomic, proteomic, metabolomic, and sensory techniques to understand flavor and aroma formation in the grape and during fermentation will generate essential knowledge about the role that production processes-from the vineyard to the cellar- have on the final product presented to a consumer.

\section{Literature Cited}

Acree, T.E., J. Barnard, and D.G. Cunningham. 1984. A procedure for the sensory analysis of gas chromatographic effluents. Food Chem. 14:273-286.

Adahchour, M., J. Beens, and U.A.T. Brinkman. 2008. Recent developments in the application of comprehensive two-dimensional gas chromatography. J. Chromatogr., A 1186:67-108.

Aiken, J.W., and A.C. Noble. 1984. Comparison of the aromas of oakand glass-aged wines. Am. J. Enol. Vitic. 35:196-199.

Andrews, J.T., H. Heymann, and M. Ellersieck. 1990. Sensory and chemical analyses of Missouri Seyval blanc wines. Am. J. Enol. Vitic. 41:116-120.

Arnold, R.A., and A.C. Noble. 1979. Effect of pomace contact on the flavor of Chardonnay wine. Am. J. Enol. Vitic. 30:179-181.

Aronson, J., and S.E. Ebeler. 2004. Effect of polyphenol compounds on the headspace volatility of flavors. Am. J. Enol. Vitic. 55:13-21.

Arrhenius, S.P., L.P. McCloskey, and M. Sylvan. 1996. Chemical markers for aroma of Vitis vinifera var. Chardonnay regional wines. J. Agric. Food Chem. 44:1085-1090.
Arthur, C.L., and J. Pawliszyn. 1990. Solid phase microextraction with thermal desorption using fused silica optical fibers. Anal. Chem. 62:2145-2148.

Arthur, C.L., L.M. Killam, K.D. Buchholz, J. Pawliszyn, and J.R. Berg. 1992. Automation and optimization of solid-phase microextraction. Anal. Chem. 64:1960-1966.

Aston, F.W. 1919. LXXIV. A positive ray spectrograph. Philos. Mag. (Series 6) 38(228):707-714.

Atanasova, B., T. Thomas-Danguin, C. Chabanet, D. Langlois, S. Nicklaus, and P. Etiévant. 2005a. Perceptual interactions in odour mixtures: Odour quality in binary mixtures of woody and fruity wine odorants. Chem. Senses 30:209-217.

Atanasova, B., T. Thomas-Danguin, D. Langlois, S. Nicklaus, C. Chabanet, and P. Etiévant. 2005b. Perception of wine fruity and woody notes: Influence of peri-threshold odorants. Food Qual. Pref. 16:504-510.

Athès, V., M. Peña y Lillo, C. Bernard, R. Pérez-Correa, and I. Souchon. 2004. Comparison of experimental methods for measuring infinite dilution volatilities of aroma compounds in water/ethanol mixtures. J. Agric. Food Chem. 52:2021-2027.

Audouin, V., F. Bonnet, Z.M. Vickers, and G.A. Reineccius. 2001. Limitations in the use of odor activity values to determine important odorants in foods. In Gas Chromatography-Olfactometry. J.V. Leland et al. (eds.), pp. 156-171. ACS Symp. Series 782. Am. Chemical Society, Washington, DC.

Azenha, M., and M.T. Vasconcelos. 2002. Headspace solid-phase micro-extraction gas chromatography-mass detection method for the determination of butyltin compounds in wines. Anal. Chim. Acta 458:231-239.

Aznar, M., R. López, J.F. Cacho, and V. Ferreira. 2001. Identification and quantification of impact odorants of aged red wines from Rioja, GC-olfactometry, quantitative GC-MS, and odor evaluation of HPLC fractions. J. Agric. Food Chem. 49:2924-2929.

Babushok, V.I., P.J. Linstrom, J.J. Reed, I.G. Zenkevich, R.L. Brown, W.G. Mallard, and S.E. Stein. 2007. Development of a database of gas chromatographic retention properties of organic compounds. J. Chromatogr., A 1157:414-421.

Bailly, S., V. Jerkovic, J. Marchand-Brynaert, and S. Collin. 2006. Aroma extraction dilution analysis of Sauternes wines. Key role of polyfunctional thiols. J. Agric. Food Chem. 54:7227-7234.

Baltussen, E., P. Sandra, F. David, and C. Cramers. 1999. Stir bar sorptive extraction (SBSE), a novel extraction technique for aqueous samples: Theory and principles. J. Microcolumn Sep. 11:737-747.

Barba, C., G. Flores, and M. Herraiz. 2010. Stereodifferentiation of some chiral aroma compounds in wine using solid phase microextractions and multidimensional gas chromatography. Food Chem. 123:846-861.

Barbe, J.C., B. Pineau, and A.C. Ferreira. 2008. Instrumental and sensory approaches for the characterization of compounds responsible for wine aroma. Chem. Biodiv. 5:1170-1183.

Baxter, M.J., H.M. Crews, M.J. Dennis, I. Goodall, and D. Anderson. 1997. The determination of the authenticity of wine from its trace element composition. Food Chem. 60:443-450.

Bellomarino, S.A., X.A. Conlan, R.M. Parker, N.W. Barnett, and M.J. Adams. 2009. Geographical classification of some Australian wines by discriminant analysis using HPLC with UV and chemiluminescence detection. Talanta 80:833-838.

Benkwitz, F., L. Nicolau, C. Lund, M. Beresford, M. Wohlers, and P.A. Kilmartin. 2012. Evaluation of key odorants in Sauvignon blanc wines using three different methodologies. J. Agric. Food Chem. 60:6293-6302.

Bonnländer, B., B. Baderschneider, M. Messerer, and P. Winterhalter. 1998. Isolation of two novel terpenoid glucose esters from Riesling wine. J. Agric. Food Chem. 46:1474-1478. 
Bouchilloux, P., P. Darriet, D. Dubourdieu, R. Henry, S. Reichert, and A. Mosand1. 2000. Stereodifferentiation of 3-mercapto-2-methylpropanol in wine. Eur. Food Res. Technol. 210:349-352.

Brescia, M.A., V. Caldarola, A. De Giglio, D. Benedetti, F.P. Fanizzi, and A. Sacco. 2002. Characterization of the geographical origin of Italian red wines based on traditional and nuclear magnetic resonance spectrometric determinations. Anal. Chim. Acta 458:177-186.

Buttery, R.G., R. Teranishi, L.C. Ling, and J.G. Turnbaugh. 1990. Quantitative and sensory studies on tomato paste volatiles. J. Agric. Food Chem. 38:336-340.

Čajka, T., J. Hajšlová, J. Cochran, K. Holadová, and E. Klimánková. 2007. Solid phase microextraction-comprehensive two-dimensional gas chromatography-time-of-flight mass spectrometry for the analysis of honey volatiles. J. Sep. Sci. 30:534-546.

Câmara, J.S., M.A. Alves, and J.C. Marques. 2006. Development of headspace solid-phase microextraction-gas chromatography-mass spectrometry methodology for analysis of terpenoids in Madeira wines. Anal. Chim. Acta 555:191-200.

Câmara, J.S., M.A. Alves, and J.C. Marques. 2007. Classification of Boal, Malvazia, Sercial and Verdelho wines based on terpenoid patterns. Food Chem. 101:475-484.

Campillo, N., P. Viñas, J.I. Cacho, R. Peñalver, and M. HernándezCórdoba. 2010. Evaluation of dispersive liquid-liquid microextraction for the simultaneous determination of chlorophenols and haloanisoles in wines and cork stoppers using gas chromatography-mass spectrometry, J. Chromatogr., A 1217:7323-7330.

Campo, E., V. Ferreira, A. Escudero, and J. Cacho. 2005. Prediction of the wine sensory properties related to grape variety from dynamicheadspace gas chromatography-olfactometry data. J. Agric. Food Chem. 53:5682-5690.

Cano-López, M., A.B. Bautista-Ortín, F. Pardo-Mínguez, J.M. LópezRoca, and E. Gómez-Plaza. 2008. Sensory descriptive analysis of a red wine aged with oak chips in stainless steel tanks or used barrels: Effect of the contact time and size of the oak chips. J. Food Qual. 31:645-660.

Canuti, V., M. Conversano, M. Li Calzi, H. Heymann, M.A. Matthews, and S.E. Ebeler. 2009. Headspace solid-phase microextraction-gas chromatography-mass spectrometry for profiling free volatile compounds in Cabernet Sauvignon grapes and wines. J. Chromatogr., A 1216:3012-3022.

Capone, D.L., K.H. Pardon, A.G. Cordente, and D.W. Jeffery. 2011. Identification and quantitation of 3-S-cysteinylglycinehexan-1-ol (cysgly-3-MH) in Sauvignon blanc grape juice by HPLC-MS/MS. J. Agric. Food Chem. 59:11204-11210.

Capone, D.L., M.A. Sefton, Y. Hayasaka, and D.W. Jeffery. 2010. Analysis of precursors to wine odorant 3-mercaptohexan-1-ol using HPLC-MS/MS: Resolution and quantitation of diastereomers of 3-S-cysteinylhexan-1-ol and 3-S-glutathionylhexan-1-ol. J. Agric. Food Chem. 58:1390-1395.

Caputi, L., S. Carlin, I. Ghiglieno, M. Stefanini, L. Valenti, U. Vrhovsek, and F. Mattivi. 2011. Relationship of changes in rotundone content during grape ripening and winemaking to manipulation of the 'peppery' character of wine. J. Agric. Food Chem. 59:5565-5571.

Cardeal, Z.L., M.D.R. Gomes Da Silva, and P.J. Marriott. 2006. Comprehensive two-dimensional gas chromatography/mass spectrometric analysis of pepper volatiles. Rapid Commun. Mass Spectrom. 20:2823-2836.

Cardeal, Z.L., P.P. de Souza, M.D.R. Gomes Da Silva, and P.J. Marriott. 2008. Comprehensive two-dimensional gas chromatography for fingerprint pattern recognition in cachaça production. Talanta 74:793-799.

Carrillo, J.D., A. Garrido-López, and M.T. Tena. 2006. Determination of volatile oak compounds in wine by headspace solid-phase microextraction and gas chromatography-mass spectrometry. J. Chromatogr., A 1102:25-36.

Castro, R., R. Natera, P. Benitez, and C.G. Barroso. 2004. Comparative analysis of volatile compounds of 'fino' sherry wine by rotatory and continuous liquid-liquid extraction and solid-phase microextraction in conjunction with gas chromatography-mass spectrometry. Anal. Chim. Acta 513:141-150.

Castro Mejías, R., R. Natera Marín, M.D.A. García Moreno, and C. García Barroso. 2003. Optimisation of headspace solid-phase microextraction for the analysis of volatile phenols in wine. J. Chromatogr., A 995:11-20.

Chapman, D.M., M.A. Matthews, and J.X. Guinard. 2004. Sensory attributes of Cabernet Sauvignon wines made from vines with different crop yields. Am. J. Enol. Vitic. 55:325-334.

Chapman, D.M., G. Roby, S.E. Ebeler, J.X. Guinard, and M.A. Matthews. 2005. Sensory attributes of Cabernet Sauvignon wines made from vines with different water status. Aust. J. Grape Wine Res. 11:339-347.

Christian, G. D. 2007. Analytical Chemistry. 6th ed. Wiley \& Sons, New York.

Collins, T.S., A. Hjelmeland, and S.E. Ebeler. 2012. Analysis of haloanisoles in corks and wines. In Recent Advances in the Analysis of Food and Flavors. S. Toth and C. Mussinan (eds.), pp. 109-127. ACS Symp. Series 1098. Am. Chemical Society, Washington, DC.

Conner, J.M., L. Birkmyre, A. Paterson, and J.R. Piggott. 1998. Headspace concentrations of ethyl esters at different alcoholic strengths. J. Sci. Food Agric. 77:121-126.

Conner, J.M., A. Paterson, and J.R. Piggott. 1994. Interactions between ethyl esters and aroma compounds in model spirit solutions. J. Agric. Food Chem. 42:2231-2234.

Cooper, H.J., and A.G. Marshall. 2001. Electrospray ionization Fourier transform mass spectrometric analysis of wine. J. Agric. Food Chem. 49:5712-5718.

Cortada, C., L. Vidal, and A. Canals. 2011. Determination of geosmin and 2-methylisoborneol in water and wine samples by ultrasoundassisted dispersive liquid-liquid microextraction coupled to gas chromatography-mass spectrometry. J. Chromatogr., A 1218:17-22.

Cortell, J.M., H.K. Sivertsen, J.A. Kennedy, and H. Heymann. 2008. Influence of vine vigor on Pinot noir fruit composition, wine chemical analysis, and wine sensory attributes. Am. J. Enol. Vitic. 59:1-10.

Cox, A., D.L. Capone, G.M. Elsey, M.V. Perkins, and M.A. Sefton. 2005. Quantitative analysis, occurrence, and stability of $(E)$ 1-(2,3,6-trimethylphenyl)buta-1,3-diene in wine. J. Agric. Food Chem. 53:3584-3591.

Cozzolino, D., W.U. Cynkar, N. Shah, and P.A. Smith. 2010. Can spectroscopy geographically classify Sauvignon blanc wines from Australia and New Zealand? Food Chem. 126:673-678.

Cuadros-Inostroza, A., P. Giavalisco, J. Hummel, A. Eckardt, L. Willmitzer, and H. Peña-Cortés. 2010. Discrimination of wine attributes by metabolome analysis. J. Agric. Food Chem. 82:3573-3580.

Cynkar, W., R. Dambergs, P. Smith, and D. Cozzolino. 2010. Classification of Tempranillo wines according to geographic origin: Combination of mass spectrometry based electronic nose and chemometrics. Anal. Chim. Acta 660:227-231.

Czerny, M., M. Christlbauer, A. Fischer, M. Granvogl, M. Hammer, C. Hartl, N.M. Hernandez, and P. Schieberle. 2008. Re-investigation on odour thresholds of key food aroma compounds and development of an aroma language based on odour qualities of defined aqueous odorant solutions. Eur. Food Res. Technol. 228:265-273.

Dallüge, J., J. Beens, and U.A.T. Brinkman. 2003. Comprehensive two-dimensional gas chromatography: A powerful and versatile analytical tool. J. Chromatogr., A 1000:69-108. 
Dandeneau, R.D., and E.H. Zerenner. 1979. An investigation of glasses for capillary chromatography. J. High Res. Chromatogr. 2:351-356.

Darriet, P., S. Lamy, S. La Guerche, M. Pons, D. Dubourdieu, D. Blancard, P. Steliopoulos, and A. Mosandl. 2001. Stereodifferentiation of geosmin in wine. Eur. Food Res. Technol. 213:122-125.

de Hoffmann, E. 1996. Tandem mass spectrometry: A primer. J. Mass Spectrom. 31:129-137.

De La Calle García, D., M. Reichenbächer, K. Danzer, C. Hurlbeck, C. Bartzsch, and K.H. Feller. 1998. Analysis of wine bouquet components using headspace solid-phase microextraction-capillary gas chromatography. J. High Res. Chromatogr. 21:373-377.

De La Presa-Owens, C., and A.C. Noble. 1997. Effect of storage at elevated temperatures on aroma of Chardonnay wines. Am. J. Enol. Vitic. 48:310-316.

Dehaene, S. 2003. The neural basis of the Weber-Fechner law: A logarithmic mental number line. Trends Cogn. Sci. 7:145-147.

Deibler, K.D., T.E. Acree, and E.H. Lavin. 1999. Solid phase microextraction application in gas chromatography/olfactometry dilution analysis. J. Agric. Food Chem. 47:1616-1618.

Demyttenaere, J.C.R., C. Dagher, P. Sandra, S. Kallithraka, R. Verhe, and N. De Kimpe. 2003. Flavour analysis of Greek white wine by solid-phase microextraction-capillary gas chromatography-mass spectrometry. J. Chromatogr., A 985:233-246.

Dufour, C., and C.L. Bayonove. 1999a. Influence of wine structurally different polysaccharides on the volatility of aroma substances in a model system. J. Agric. Food Chem. 47:671-677.

Dufour, C., and C. L. Bayonove. 1999b. Interactions between wine polyphenols and aroma substances. An insight at the molecular level. J. Agric. Food Chem. 47:678-684.

Ebeler, S.E. 2001. Analytical chemistry: Unlocking the secrets of wine flavor. Food Rev. Int. 17:45-64.

Ebeler, S.E. 2012. Gas chromatographic analysis of wines: Current applications and future trends. In Gas Chromatography. C.F. Poole (ed.), pp. 689-710. Elsevier, Amsterdam.

Ebeler, S.E., and J.H. Thorngate. 2009. Wine chemistry and flavor: Looking into the crystal glass. J. Agric. Food Chem. 57:8098-8108.

Eglinton, J.M., S.J. McWilliam, M.W. Fogarty, I.L. Francis, M.J. Kwiatkowski, P.B. Høj, and P.A. Henschke. 2000. The effect of Saccharomyces bayanus-mediated fermentation on the chemical composition and aroma profile of Chardonnay wine. Aust. J. Grape Wine Res. 6:190-196.

Escalona, J.M., J. Flexas, H.R. Schultz, and H. Medrano. 1999. Effect of moderate irrigation on aroma potential and other markers of grape quality. In Proceedings of the First ISHS Workshop on Water Relations of Grapevines. E. Rühl and J. Schmid (eds.), pp. 261-268. Int. Society for Horticultural Science, Berlin.

Escudero, A., E. Campo, L. Fariña, J. Cacho, and V. Ferreira. 2007. Analytical characterization of the aroma of five premium red wines. Insights into the role of odor families and the concept of fruitiness of wines. J. Agric. Food Chem. 55:4501-4510.

Escudero, A., B. Gogorza, M.A. Melús, N. Ortín, J. Cacho, and V. Ferreira. 2004. Characterization of the aroma of a wine from Maccabeo. Key role played by compounds with low odor activity values. J. Agric. Food Chem. 52:3516-3524.

Falqué, E., A.C. Ferreira, T. Hogg, and P. Guedes de Pinho. 2004. Determination of aromatic descriptors of Touriga Nacional wines by sensory descriptive analysis. Flavour Fragr. J. 19:298-302.

Farelo, F., A.M.C. Lopes, and M.I. Ferra. 2004. Solubilities of sodium chloride and potassium chloride in water + ethanol mixtures from (298 to 323) K. J. Chem. Eng. Data 49:1782.

Fedrizzi, B., K.H. Pardon, M.A. Sefton, G.M. Elsey, and D.W. Jeffery. 2009. First identification of 4-S-glutathionyl-4-methylpentan-2-one, a potential precursor of 4-mercapto-4-methylpentan-2-one, in Sauvignon blanc juice. J. Agric. Food Chem. 57:991-995.

Fernandes, L., A.M. Relva, M.D. da Silva, and A.M. Freitas. 2003. Different multidimensional chromatoraphic approaches applied to the study of wine malolactic fermentation. J. Chromatogr., A 995:161-169.

Ferreira, V., M. Aznar, R. López, and J. Cacho. 2001. Quantitative gas chromatography-olfactometry carried out at different dilutions of an extract. Key differences in the odor profiles of four high-quality Spanish aged red wines. J. Agric. Food Chem. 49:4818-4824.

Ferreira, V., N. Ortín, A. Escudero, R. López, and J. Cacho. 2002. Chemical characterization of the aroma of Grenache rosé wines: Aroma extract dilution analysis, quantitative determination, and sensory reconstitution studies. J. Agric. Food Chem. 50:4048-4054.

Fischer, C., and U. Fischer. 1997. Analysis of cork taint in wine and cork material at olfactory subthreshold levels by solid phase microextraction. J. Agric. Food Chem. 45:1995-1997.

Fischer, U., D. Roth, and M. Christmann. 1999. The impact of geographic origin, vintage and wine estate on sensory properties of Vitis vinifera cv. Riesling wines. Food Qual. Pref. 10:281-288.

Flath, R. 1977. Symposium on methods for the isolation of trace volatile constituents. J. Agric. Food Chem. 25:439.

Fontana, A.R., S.H. Patil, K. Banerjee, and J.C. Altamirano. 2010. Ultrasound-assisted emulsification microextraction for determination of 2,4,6-trichloroanisole in wine samples by gas chromatography tandem mass spectrometry. J. Agric. Food Chem. 58:4576-4581.

Francis, I.L., and J.L. Newton. 2005. Determining wine aroma from compositional data. Aust. J. Grape Wine Res. 11:114-126.

Francis, I.L., M.A. Sefton, and P.J. Williams. 1992. A study by sensory descriptive analysis of the effects of oak origin, seasoning, and heating on the aromas of oak model wine extracts. Am. J. Enol. Vitic. 43:23-30.

Francis, I.L., M.A. Sefton, and P.J. Williams. 1994. The sensory effects of pre- or post-fermentation thermal processing on Chardonnay and Semillon wines. Am. J. Enol. Vitic. 45:243-251.

Frank, S., N. Wollmann, P. Schieberle, and T. Hofmann. 2011. Reconstitution of the flavor signature of Dornfelder red wine on the basis of the natural concentrations of its key aroma and taste compounds. J. Agric. Food Chem. 59:8866-8874.

Frías, S., J.E. Conde, J.J. Rodríguez-Bencomo, F. García-Montelongo, and J.P. Pérez-Trujillo. 2003. Classification of commercial wines from the Canary Islands (Spain) by chemometric techniques using metallic contents. Talanta 59:335-344.

Friedrich, J.E., and T.E. Acree. 2002. Analyzing carotenoid-derived aroma compounds using gas chromatography-olfactometry. In Carotenoid-Derived Aroma Compounds. P. Winterhalter and R. Rouseff (eds.), pp. 67-74. ACS Symposium Series 802. Am. Chemical Society, Washington, DC.

Fuller, G.H., R. Steltenkamp, and G.A. Tisserand. 1964. The gas chromatograph with human sensor: Perfumer model. Ann. N.Y. Acad. Sci. 116:711-724.

Furbo, S., and J. H. Christensen. 2012. Automated peak extraction and quantification in chromatography with multichannel detectors. Anal. Chem. 84:2211-2218.

Gawel, R. 1998. Red wine astringency: A review. Aust. J. Grape Wine Res. 4:74-95.

Gawel, R., L. Francis, and E.J. Waters. 2007. Statistical correlations between the in-mouth textural characteristics and the chemical composition of Shiraz wines. J. Agric. Food Chem. 55:2683-2687.

Gawel, R., A. Oberholster, and I.L. Francis. 2000. A 'Mouth-feel Wheel': Terminology for communicating the mouth-feel characteristics of red wine. Aust. J. Grape Wine Res. 6:203-207.

Genovese, A., A. Gambuti, P. Piombino, and L. Moio. 2007. Sensory properties and aroma compounds of sweet Fiano wine. Food Chem. 103:1228-1236. 
Godden, P., L. Francis, J. Field, M. Gishen, A. Coulter, P. Valente, P. Høj, and E. Robinson. 2001. Wine bottle closures: Physical characteristics and effect on composition and sensory properties of a Semillon wine 1. Performance up to 20 months post-bottling. Aust. J. Grape Wine Res. 7:64-105.

Goldner, M.C., and M.C. Zamora. 2007. Sensory characterization of Vitis vinifera $\mathrm{cv}$. Malbec wines from seven viticulture regions of Argentina. J. Sens. Studies 22:520-532.

Gomez-Cortez, P., J.T. Brenna, and G.L. Sacks. 2012. Production of isotopically labeled standards from a uniformly labeled precursor for quantitative volatile metabolomics studies. Anal. Chem. $84: 5400-5406$

Górecki, T., J. Harynuk, and O. Panic. 2004. The evolution of comprehensive two-dimensional gas chromatography (GC x GC). J. Sep. Sci. 27:359-379.

Gougeon, R.D., et al. 2009. The chemodiversity of wines can reveal a metabologeography expression of cooperage oak wood. Proc. Natl. Acad. Sci. 106:9174-9179.

Grosch, W. 2001. Evaluation of the key odorants of foods by dilution experiments, aroma models and omission. Chem. Senses 26:533-545.

Guinard, J.X., and M. Cliff. 1987. Descriptive analysis of Pinot noir wines from Carneros, Napa, and Sonoma. Am. J. Enol. Vitic. $38: 211-215$

Günata, Y.Z., C.L. Bayonove, R.L. Baumes, and R.E. Cordonnier. 1985. The aroma of grapes. I. Extraction and determination of free and glycosidically bound fractions of some grape aroma components. J. Chromatogr., A 331:83-90.

Günata, Z., I. Dugelay, J.C. Sapis, R. Baumes, and C. Bayonove. 1993. Role of enzymes in the use of the flavour potential from grape glycosides in winemaking. In Progress in Flavour Precursor Studies: Analysis, Generation, Biotechnology. P. Schreier and P. Winterhalter (eds.), pp. 219-234. Allured Publishing, Carol Stream, IL.

Guth, H. 1997a. Identification of character impact odorants of different white wine varieties. J. Agric. Food Chem. 45:3022-3026.

Guth, H. 1997b. Quantitation and sensory studies of character impact odorants of different white wine varieties. J. Agric. Food Chem. 45:3027-3032.

Guth, H. 1998. Comparison of different white wine varieties in odor profiles by instrumental analysis and sensory studies. In Chemistry of Wine Flavor. A.L. Waterhouse and S.E. Ebeler (eds.), pp. 39-52. ACS Symp. Series 714. Am. Chemical Society, Washington, DC.

Guyot-Declerck, C., F. Chevance, G. Lermusieau, and S. Collin. 2000. Optimized extraction procedure for quantifying norisoprenoids in honey and honey food products. J. Agric. Food Chem. 48:5850-5855.

Hakimi Rezaei, J., and A.G. Reynolds. 2010. Characterization of Niagara Peninsula Cabernet franc wines by sensory analysis. Am. J. Enol. Vitic. 61:1-14.

Harris, D.C. 2003. Quantitative Chemical Analysis. 6th ed. Macmillan, New York.

Hartmann, P.J., H.M. McNair, and B.W. Zoecklein. 2002. Measurement of 3-alkyl-2-methoxypyrazine by headspace solid-phase microextraction in spiked model wines. Am. J. Enol. Vitic. 53:285-288.

Hayasaka, Y., G.A. Baldock, and A.P. Pollnitz. 2005. Contributions of mass spectrometry in the Australian Wine Research Institute to advances in knowledge of grape and wine constituents. Aust. J. Grape Wine Res. 11:188-204.

Hayasaka, Y., G.A. Baldock, K.H. Pardon, D.W. Jeffery, and M.J. Herderich. 2010a. Investigation into the formation of guaiacol conjugates in berries and leaves of grapevine Vitis vinifera L. cv. Cabernet Sauvignon using stable isotope tracers combined with HPLC-MS and MS/MS analysis. J. Agric. Food Chem. 58:2076-2081.

Hayasaka, Y., G.A. Baldock, M. Parker, K.H. Pardon, C.A. Black, M.J. Herderich, and D.W. Jeffery. 2010b. Glycosylation of smoke-derived volatile phenols in grapes as a consequence of grapevine exposure to bushfire smoke. J. Agric. Food Chem. 58:10989-10998.

Hein, K., S.E. Ebeler, and H. Heymann. 2009. Perception of fruity and vegetative aromas in red wine. J. Sens. Studies 24:441-455.

Herszage, J. and S.E. Ebeler. 2011. Analysis of volatile organic sulfur compounds in wine using headspace solid-phase microextraction gas chromatograpy with sulfur chemiluminescence detection. Am. J. Enol. Vitic. 62:1-8.

Heymann, H., and A.C. Noble. 1987. Descriptive analysis of commercial Cabernet Sauvignon wines from California. Am. J. Enol. Vitic. 38:41-44.

Hjelmeland, A.K., T.S. Collins, J.L. Miles, P.L. Wylie, A.E. Mitchell, and S.E. Ebeler. 2012. High-throughput, sub ng/L analysis of haloanisoles in wines using HS-SPME with GC-triple quadrupole MS. Am. J. Enol. Vitic. 63:494-499.

Hjelmeland, A.K., E.S. King, S.E. Ebeler, and H. Heymann. 2013. Characterizing the chemical and sensory profiles of United States Cabernet Sauvignon wines and blends. Am. J. Enol. Vitic. 64:169-179.

Hopfer, H., P.A. Buffon, S.E. Ebeler, and H. Heymann. 2013. The combined effects of storage temperature and packaging on the sensory, chemical, and physical properties of a Cabernet Sauvignon wine. J. Agric. Food Chem. 61:3320-3334.

Hopfer, H., S.E. Ebeler, and H. Heymann. 2012a. How blending affects the sensory and chemical properties of red wine. Am. J. Enol. Vitic. 63:313-324.

Hopfer, H., S.E. Ebeler, and H. Heymann. 2012b. The combined effects of storage temperature and packaging type on the sensory and chemical properties of Chardonnay. J. Agric. Food Chem. 60:10743-10754.

Howard, K.L., J.H. Mike, and R. Riesen. 2005. Validation of a solidphase microextraction method for headspace analysis of wine aroma components. Am. J. Enol. Vitic. 56:37-45.

James, A.T., and A.J.P. Martin. 1952. Gas-liquid partition chromatography: The separation and micro-estimation of volatile fatty acids from formic acid to dodecanoic acid. Biochem. J. 50:679-690.

Jelen, H.H., M. Majcher, and M. Dziadas. 2012. Microextraction techniques in the analysis of food flavor compounds: A review. Anal. Chim. Acta 738:13-26.

Jennings, W.G., and M. Filsoof. 1977. Comparison of sample preparation techniques for gas chromatographic analysis. J. Agric. Food Chem. 25:440-445.

Jiang, W., Y. Qiu, Y. Ni, M. Su, W. Jia, and X. Du. 2010. An automated data analysis pipeline for GC-TOF-MS metabonomics studies. J. Proteome Res. 9:5974-5981.

Jofré, V.P., M.V. Assof, M.L. Fanzone, H.C. Goicoechea, L.D. Martínez, and M.F. Silva. 2010. Optimization of ultrasound assisted-emulsification-dispersive liquid-liquid microextraction by experimental design methodologies for the determination of sulfur compounds in wines by gas chromatography-mass spectrometry. Anal. Chim. Acta 683:126-135.

Johnson, A.J., G.D. Hirson, and S.E. Ebeler. 2012. Perceptual characterization and analysis of aroma mixtures using gas chromatography recomposition-olfactometry. PLoS ONE 7:e42693.

Jones, P.R., R. Gawel, I.L. Francis, and E.J. Francis. 2008. The influence of interactions between major white wine components on the aroma, flavour and texture of model white wine. Food Qual. Pref. 19:596-607.

Jung, D.M., and S.E. Ebeler. 2003. Headspace solid-phase microextraction method for the study of the volatility of selected flavor compounds. J. Agric Food Chem. 51:200-205.

Jung, D.M., J.S. de Ropp, and S.E. Ebeler. 2000. Study of interactions between food phenolics and aromatic flavors using one- and twodimensional ${ }^{1}$ H NMR spectroscopy. J. Agric. Food Chem. 48:407-412. 
Jung, D.M., J.S. de Ropp, and S.E. Ebeler. 2002. Application of pulsed field gradient NMR techniques for investigating binding of flavor compounds to macromolecules. J. Agric. Food Chem 50:4262-4269.

Kataoka, H., H.L. Lord, and J. Pawliszyn. 2000. Applications of solidphase microextraction in food analysis. J. Chromatogr., A 880:35-62.

King, E.S., R.L. Dunn, and H. Heymann. 2013. The influence of alcohol on the sensory perception of red wines. Food Qual. Pref. 28:235-243.

King, E.S., M. Stoumen, F. Buscema, A.K. Hjelmeland, S.E. Ebeler, H. Heymann, and R.B. Boulton. 2014. Regional sensory and chemical characteristics of Malbec wines from Mendoza and California. Food Chem. 143:256-267.

Kloskowski, A., W. Chrzanowski, M. Pilarczyk, and J. Namiesnik. 2007. Modern techniques of sample preparation for determination of organic analytes by gas chromatography. Crit. Rev. Anal. Chem. 37:15-38.

Kobayashi, H., H. Takase, Y. Suzuki, F. Tanzawa, R. Takata, K. Fujita, M. Kohno, M. Mochizuki, S. Suzuki, and T. Konno. 2011. Environmental stress enhances biosynthesis of flavor precursors, $S$-3-(hexan-1-ol)-glutathione and $S$-3-(hexan-1-01)-L-cysteine, in grapevine through glutathione $S$-transferace activation. J. Exp. Bot. 62:1325-1336.

Kotseridis, Y., and R. Baumes. 2000. Identification of impact odorants in Bordeaux red grape juice, in the commercial yeast used for its fermentation, and in the produced wine. J. Agric. Food Chem. 48:400-406.

Lancas, F.M., M.E.C. Queiroz, P. Grossi, and I.R.B. Olivares. 2009. Recent developments and applications of stir bar sorptive extraction. J. Sep. Sci. 32:813-824.

Lattey, K.A., B.R. Bramley, and I.L. Francis. 2010. Consumer acceptability, sensory properties and expert quality judgements of Australian Cabernet Sauvignon and Shiraz wines. Aust. J. Grape Wine Res. 16:189-202.

Lawless, H.T., and H. Heymann. 2010. Sensory Evaluation of Food: Principles and Practices. Springer, New York.

Le Berre, E., B. Atanasova, D. Langlois, P. Etiévant, and T. ThomasDanguin. 2007. Impact of ethanol on the perception of wine odorant mixtures. Food Qual. Pref. 18:901-908.

Lee, S.J., and A.C. Noble. 2003. Characterization of odor-active compounds in Californian Chardonnay wines using GC-olfactometry and GC-mass spectrometry. J. Agric. Food Chem. 51:8036-8044.

Lee, S.J., and A.C. Noble. 2006. Use of partial least squares regression and multidimensional scaling on aroma models of California Chardonnay wines. Am. J. Enol. Vitic. 57:363-370.

Lesschaeve, I. 2007. Sensory evaluation of wine and commercial realities: Review of current practices and perspectives. Am. J. Enol. Vitic. 58:252-258.

Lestremau, F., F.A.T. Andersson, and V. Desauziers. 2004. Investigation of artefact formation during analysis of volatile sulphur compounds using solid phase microextraction (SPME). Chromatographia 59:607-613.

Liger-Belair, G., C. Cilindre, R. D. Gougeon, M. Lucio, I. Gebefügi, P. Jeandet, and P. Schmitt-Kopplin. 2009. Unraveling different chemical fingerprints between a champagne wine and its aerosols. Proc. Natl. Acad. Sci. 106:16545-16549.

Liu, L., D. Cozzolino, W.U. Cynkar, M. Gishen, and C.B. Colby. 2006. Geographic classification of Spanish and Australian Tempranillo red wines by visible and near-infrared spectroscopy combined with multivariate analysis. J. Agric. Food Chem. 54:6754-6759.

Liu, Z., and J.B. Phillips. 1991. Comprehensive two-dimensional gas chromatography using an on-column thermal modulator interface. J. Chromatogr. Sci. 29:227-231.

Lloyd, N.W., S.R. Dungan, and S.E. Ebeler. 2011. Measuring gas-liquid partition coefficients of aroma compounds by solid phase microextraction, sampling either headspace or liquid. Analyst 136:3375-3383.
Lockshin, L., W. Jarvis, F. d'Hauteville, and J.P. Perrouty. 2006. Using simulations from discrete choice experiments to measure consumer sensitivity to brand, region, price, and awards in wine choice. Food Qual. Pref. 17:166-178.

López, R., V. Ferreira, P. Hernández, and J.F. Cacho. 1999. Identification of impact odorants of young red wines made with Merlot, Cabernet Sauvignon and Grenache grape varieties: A comparative study. J. Sci. Food Agric. 79:1461-1467.

López, R., N. Ortín, J.P. Pérez-Trujillo, J. Cacho, and V. Ferreira. 2003. Impact odorants of different young white wines from the Canary Islands. J. Agric. Food Chem. 51:3419-3425.

Luan, F., A. Degenhardt, A. Mosandl, and M. Wüst. 2006. Mechanism of wine lactone formation: Demonstration of stereoselective cyclization and 1,3-hydride shift. J. Agric. Food Chem. 54:10245-10252.

Lund, C.M., M.K. Thompson, F. Benkwitz, M.W. Wohler, C.M. Triggs, R. Gardner, H. Heymann, and L. Nicolau. 2009. New Zealand Sauvignon blanc distinct flavor characteristics: Sensory, chemical, and consumer aspects. Am. J. Enol. Vitic. 60:1-12.

Madrigal-Galan, B., and H. Heymann. 2006. Sensory effects of consuming cheese prior to evaluating red wine flavor. Am. J. Enol. Vitic. 57:12-22.

Marais, J., and H. Pool. 1980. Effect of storage time and temperature on the volatile composition and quality of dry white table wines. Vitis 19:151-164.

Marchal, A., P. Waffo-Téguo, E. Génin, J.M. Mérillon, and D. Dubourdieu. 2011. Identification of new natural sweet compounds in wine using centrifugal partition chromatography-gustatometry and Fourier transform mass spectrometry. Anal. Chem. 83:9629-9637.

Marengo, E., M. Aceto, and V. Maurino. 2002. Classification of Nebbiolo-based wines from Piedmont (Italy) by means of solid-phase microextraction-gas chromatography-mass spectrometry of volatile compounds. J. Chromatogr., A 943:123-137.

Marinos, V.A., M.E. Tate, and P.J. Williams. 1994. Protocol for FAB MS/MS characterization of terpene disaccharides of wine. J. Agric. Food Chem. 42:2486-2492.

Masson, G., and R. Schneider. 2009. Key compounds of Provence rosé wine flavor. Am. J. Enol. Vitic. 60:116-122.

Mateo, J.J., N. Gentilini, T. Huerta, M. Jiménez, and R. Di Stefano. 1997. Fractionation of glycoside precursors of aroma in grapes and wine. J. Chromatogr., A 778:219-224.

Mattivi, F., L. Caputi, S. Carlin, T. Lanza, M. Minozzi, D. Nanni, L. Valenti, and U. Vrhovsek. 2011. Effective analysis of rotundone at below-threshold levels in red and white wines using solid-phase microextraction gas chromatography/tandem mass spectrometry. Rapid Comm. Mass Spectrom. 25:483-488.

Mazo, R.M. 2006. A fluctuation theory analysis of the salting-out effect. J. Phys. Chem. B 110:24077-24082.

Mestres, M., M.P. Marti, O. Busto, and J. Guasch. 1999a. Simultaneous analysis of thiols, sulphides and disulphides in wine aroma by headspace solid-phase microextraction-gas chromatography. J. Chromatogr., A 849:293-297.

Mestres, M., C. Sala, M.P. Marti, O. Busto, and J. Guasch. 1999b. Headspace solid-phase microextraction of sulphides and disulphides using carboxen-polydimethylsiloxane fibers in the analysis of wine aroma. J. Chromatogr., A 835:137-144.

Montes, R., I. Rodríguez, M. Ramil, E. Rubi, and R. Cela. 2009. Solid-phase extraction followed by dispersive liquid-liquid microextraction for the sensitive determination of selected fungicides in wine. J. Chromatogr., A 1216:5459-5466.

Muñoz-González, C., J.J. Rodríguez-Bencomo, M.V. Moreno-Arribas, and M.Á. Pozo-Bayón. 2011. Beyond the characterization of wine aroma compounds: Looking for analytical approaches in trying 
to understand aroma perception during wine consumption. Anal. Bioanal. Chem. 401:1497-1512.

Murray, J.M., C.M. Delahunty, and I.A. Baxter. 2001. Descriptive sensory analysis: Past, present and future. Food Res. Int. 34:461-471.

Murray, K.K., R.K. Boyd, M.N. Eberlin, G.J. Langley, L. Li, and Y. Naito. 2013. Definitions of terms relating to mass spectrometry (IUPAC recommendations 2013). Pure Appl. Chem. 85:1515-1609.

Murray, R.A. 2001. Limitations to the use of solid-phase microextraction for quantitation of mixtures of volatile organic sulfur compounds. Anal. Chem. 73:1646-1649.

Naes, T., P. Brockhoff, and O. Tomic. 2011. Statistics for Sensory and Consumer Science. Wiley \& Sons, Chichester, UK.

Nasi, A., P. Ferranti, S. Amato, and L. Chianese. 2008. Identification of free and bound volatile compounds as typicalness and authenticity markers of non-aromatic grapes and wines through a combined use of mass spectrometric techniques. Food Chem. 110:762-768.

Noble, A.C., and S.E. Ebeler. 2002. Use of multivariate statistics in understanding wine flavor. Food Rev. Int. 18:1-21.

Noble, A.C., and M. Shannon. 1987. Profiling Zinfandel wines by sensory and chemical analyses. Am. J. Enol. Vitic. 38:1-5.

Noble, A.C., R.A. Arnold, B.M. Masuda, S.D. Pecore, J.O. Schmidt, and P.M. Stern. 1984. Progress towards a standardized system of wine aroma terminology. Am. J. Enol. Vitic. 35:107-109.

Noble, A.C., R.A. Arnold, J. Buechsenstein, E.J. Leach, J.O. Schmidt, and P.M. Stern. 1987. Modification of a standardized system of wine aroma terminology. Am. J. Enol. Vitic. 38:143-146.

Ong, R.C.Y., and P.J. Marriott. 2002. A review of basic concepts in comprehensive two-dimensional gas chromatography. J. Chromatogr. Sci. 40:276-291.

Ortega-Heras, M., M.L. Gonzalez-SanJose, and S. Beltran. 2002. Aroma composition of wine studied by different extraction methods. Anal. Chim. Acta 458:85-93.

Palma, M., L.T. Taylor, B.W. Zoecklein, and L.S. Douglas. 2000. Supercritical fluid extraction of grape glycosides. J. Agric. Food Chem. 48:775-779.

Pan, L., M. Adams, and J. Pawliszyn. 1995. Determination of fatty acids using solid-phase microextraction. Anal. Chem. 67:4396-4403.

Pena-Pereira, F., I. Lavilla, and C. Bendicho. 2009. Miniaturized preconcentration methods based on liquid-liquid extraction and their application in inorganic ultratrace analysis and speciation: A review. Spectrochim. Acta B 54:1-15.

Perestrelo, R., S. Petronilho, J.S. Câmara, and S.M. Rocha. 2010. Comprehensive two-dimensional gas chromatography with time-of-flight mass spectrometry combined with solid phase microextraction as a powerful tool for quantification of ethyl carbamate in fortified wines. The case study of Madeira wine. J. Chromatogr., A 1217:3441-3445.

Perez-Cacho, P.R., and R. Rouseff. 2008. Processing and storage effects on orange juice aroma: A review. J. Agric. Food Chem. 56:9785-9796.

Pérez-Coello, M.S., M.A. González-Viñas, E. García-Romero, M.C. Díaz-Maroto, and M.D. Cabezudo. 2003. Influence of storage temperature on the volatile compounds of young white wines. Food Control 14:301-306.

Peryam, D.R., and V.W. Swartz. 1950. Measurement of sensory differences. Food Technol. 4:390-395.

Pineau, B., J.C. Barbe, C. Van Leeuwen, and D. Dubourdieu. 2007. Which impact for $\beta$-damascenone on red wines aroma? J. Agric. Food Chem. 55:4103-4108.

Pineau, B., J.C. Barbe, C. Van Leeuwen, and D. Dubourdieu. 2009. Examples of perceptive interactions involved in specific "red-" and "black-berry" aromas in red wines. J. Agric. Food Chem. 57:37023708 .
Pizarro, C., C. Sáenz-González, N. Perez-del-Notario, and J.M. González-Sálz. 2010. Optimisation of a dispersive liquid-liquid microextraction method for the simultaneous determination of halophenols and haloanisoles in wines. J. Chromatogr., A 1217:7630-7637.

Pizarro, C., C. Saenz-Gonzalez, N. Perez-del-Notario, and J.M. Gonzalez-Saiz. 2011a. Development of a dispersive liquid-liquid microextraction method for the simultaneous determination of the main compounds causing cork taint and Brett character in wines using gas chromatography-tandem mass spectrometry. J. Chromatogr., A $1218: 1576-1584$.

Pizarro, C., C. Saenz-Gonzalez, N. Perez-del-Notario, and J.M. Gonzalez-Saiz. 2011b. Ultrasound assisted emulsification-microextraction for the sensitive determination of Brett character responsible compounds in wines. J. Chromatogr., A 1218:8975-8981.

Plug, H., and P. Haring. 1994. The influence of flavour-ingredient interactions on flavour perception. Food Qual. Pref. 5:95-102.

Plutowska, B., and W. Wardencki. 2008. Application of gas chromatography-olfactometry (GC-O) in analysis and quality assessment of alcoholic beverages-A review. Food Chem. 107:449-463.

Polášková, P., J. Herszage, and S.E. Ebeler. 2008. Wine flavor: Chemistry in a glass. Chem. Soc. Rev. 37:2478-2489.

Preston, L.D., D.E. Block, H. Heymann, G. Soleas, A.C. Noble, and S.E. Ebeler. 2008. Defining vegetal aromas in Cabernet Sauvignon using sensory and chemical evaluations. Am. J. Enol. Vitic. 59:137-145.

Prida, A., and P. Chatonnet. 2010. Impact of oak-derived compounds on the olfactory perception of barrel-aged wines. Am. J. Enol. Vitic. 61:408-413.

Ramey, D.D., and C.S. Ough. 1980. Volatile ester hydrolysis or formation during storage of model solutions and wines. J. Agric. Food Chem. 28:928-934.

Rauhut, D., H. Körbel, K. MacNamara, and M. Grossmann. 1998. Headspace GC-SCD monitoring of low volatile sulfur compounds during fermentation and in wine. Analusis 26:142-145.

Razungles, A., Z. Gunata, S. Pinatel, R. Baumes, and C. Bayonove. 1993. Quantitative studies on terpenes, norisoprenoids and their precursors in several varietes of grapes. Sci. Aliments 13:59-72.

Reynolds, A., M. Cliff, B. Girard, and T.G. Kopp. 2001. Influence of fermentation temperature on composition and sensory properties of Semillon and Shiraz wines. Am. J. Enol. Vitic. 52:235-240.

Reynolds, A.G., G. Taylor, and C. de Savigny. 2013. Defining Niagara terroir by chemical and sensory analysis of Chardonnay wines from various soil textures and vine sizes. Am. J. Enol. Vitic. 64:180-194.

Reynolds, A.G., S. Yerle, B. Watson, S.F. Price, and D.A. Wardle. 1996. Fruit environment and crop level effects on Pinot noir. III. Composition and descriptive analysis of Oregon and British Columbia wines. Am. J. Enol. Vitic. 47:329-339.

Risticevic, S., H. Lord, T. Gorecki, C.L. Arthur, and J. Pawliszyn. 2010a. Protocol for solid-phase microextraction method development. Nat. Protocols 5:122-139.

Risticevic, S., Y. Chen, L. Kudlejova, R. Vatinno, B. Baltensperger, J.R. Stuff, D. Hein, and J. Pawliszyn. 2010b. Protocol for the development of automated high-throughput SPME-GC methods for the analysis of volatile and semivolatile constituents in wine samples. Nat. Protocols 5:162-176.

Robinson, A.L., D.O. Adams, P.K. Boss, H. Heymann, P.S. Solomon, and R.D. Trengove. 2011a. The relationship between sensory attributes and wine composition for Australian Cabernet Sauvignon wines. Aust. J. Grape Wine Res. 17:327-340.

Robinson, A.L., P.K. Boss, H. Heymann, P.S. Solomon, and R.D. Trengove. 2011b. Influence of yeast strain, canopy management, and site on the volatile composition and sensory attributes of Cabernet Sauvignon wines from Western Australia. J. Agric. Food Chem. 59:3273-3284. 
Robinson, A.L., P.K. Boss, H. Heymann, P.S. Solomon, and R.D. Trengove. 2011c. Development of a sensitive non-targeted method for characterizing the wine volatile profile using headspace solid-phase microextraction comprehensive two-dimensional gas chromatography time-of-flight mass spectrometry. J. Chromatogr., A 1218:504-517.

Robinson, A.L., S.E. Ebeler, H. Heymann, P.K. Boss, P.S. Solomon, and R.D. Trengove. 2009. Interactions between wine volatile compounds and grape and wine matrix components influence aroma compound headspace partitioning. J. Agric. Food Chem. 57:10313-10322.

Robinson, A.L., M. Mueller, H. Heymann, S.E. Ebeler, P.K. Boss, P.S. Solomon, and R.D. Trengove. 2010. Effect of simulated shipping conditions on sensory attributes and volatile composition of commercial white and red wines. Am. J. Enol. Vitic. 61:337-347.

Rocha, S., V. Ramalheira, A. Barros, I. Delgadillo, and M.A. Coimbra. 2001. Headspace solid phase microextraction (SPME) analysis of flavor compounds in wines. Effect of the matrix volatile composition in the relative response factors in a wine model. J. Agric. Food Chem. 49:5142-5151.

Rocha, S.M., E. Coelho, J. Zrostlíková, I. Delgadillo, and M.A. Coimbra. 2007. Comprehensive two-dimensional gas chromatography with time-of-flight mass spectrometry of monoterpenoids as a powerful tool for grape origin traceability. J. Chromatogr., A 1161:292-299.

Rodríguez-Bencomo, J.J., J.E. Conde, M.A. Rodríguez-Delgado, F. García-Montelongo, and J.P. Pérez-Trujillo. 2002. Determination of esters in dry and sweet white wines by headspace solid-phase microextraction and gas chromatography. J. Chromatogr., A 963:213-223.

Rosillo, L., M.A.R. Salinas, J. Garijo, and G.L. Alonso. 1999. Study of volatiles in grapes by dynamic headspace analysis: Application to the differentiation of some Vitis vinifera varieties. J. Chromatogr., A 847:155-159.

Ryan, D., R. Shellie, P. Tranchida, A. Casilli, L. Mondello, and P. Marriott. 2004. Analysis of roasted coffee bean volatiles by using comprehensive two-dimensional gas chromatography-time-of-flight mass spectrometry. J. Chromatogr., A 1054:57-65.

Ryan, D., P. Watkins, J. Smith, M. Allen, and P. Marriott. 2005. Analysis of methoxypyrazines in wine using headspace solid phase microextraction with isotope dilution and comprehensive two-dimensional gas chromatography. J. Sep. Sci. 28:1075-1082.

Ryona, I., B.S. Pan, and G.L. Sacks. 2009. Rapid measurement of 3-alkyl-2-methoxypyrazine content of winegrapes to predict levels in resultant wines. J. Agric. Food Chem. 57:8250-8257.

Ryona, I., B.S. Pan, D.S. Intrigliolo, A.N. Lakso, and G.L. Sacks. 2008. Effects of cluster light exposure on 3-isobutyl-2-methoxypyrazine accumulation and degradation patterns in red wine grapes (Vitis vinifera L. cv. Cabernet franc). J. Agric. Food Chem. 56:10838-10846.

Ryona, I., S. Leclerc, and G.L. Sacks. 2010. Correlation of 3-isobutyl2-methoxypyrazine to 3-isobutyl-2-hydroxypyrazine during maturation of bell pepper (Capsicum annuum) and wine grapes (Vitis vinifera). J. Agric. Food Chem. 58:9723-9730.

Sáenz-Navajas, M.P., E. Campo, L. Culleré, P. Fernández-Zurbano, D. Valentin, and V. Ferreira. 2010. Effects of the nonvolatile matrix on the aroma perception of wine. J. Agric. Food Chem. 58:5574-5585.

Sáenz-Navajas, M.P., P. Fernández-Zurbano, and V. Ferreira. 2012. Contribution of nonvolatile composition to wine flavor. Food Rev. Int. 28:389-411.

Sala, C., M. Mestres, M.P. Marti, O. Busto, and J. Guasch. 2000. Headspace solid-phase microextraction method for determining 3-alkyl-2-methoxypyrazines in musts by means of polydimethylsiloxane-divinylbenzene fibres. J. Chromatogr., A 880:93-99.

Schieberle, P., and R.J. Molyneux. 2012. Quantitation of sensory-active and bioactive constituents of food: A Journal of Agricultural and Food Chemistry perspective. J. Agric. Food Chem. 60:2404-2408.

Schmarr, H.G., J. Bernhardt, U. Fischer, A. Stephan, P. Müller, and D. Durner. 2010. Two-dimensional gas chromatographic profiling as a tool for a rapid screening of the changes in volatile composition occurring due to microoxygenation of red wines. Anal. Chim. Acta 672:114-123.

Schmarr, H.G., T. Potouridis, S. Ganss, W. Sang, B. Köpp, U. Bokuz, and U. Fischer. 2008a. Analysis of carbonyl compounds via headspace solid-phase microextraction with on-fiber derivatization and gas chromatographic-ion trap tandem mass specrometric determination of their $O$-(2,3,4,5,6-pentafluorobenzyl)oxime derivatives. Anal. Chim. Acta 617:119-131.

Schmarr, H.G., W. San, S. Ganß, U. Fischer, B. Köpp, C. Schulz, and T. Potouridis. 2008b. Analysis of aldehydes via headspace SPME with on-fiber derivatization to their $O$-(2,3,4,5,6-pentafluorobenzyl)oxime derivatives and comprehensive 2D-GC-MS. J. Sep. Sci. 31:3458-3465.

Schmidt, J.O., and A.C. Noble. 1983. Investigation of the effect of skin contact time on wine flavor. Am. J. Enol. Vitic. 34:135-138.

Schneider, R., Y. Kotseridis, J.L. Ray, C. Augier, and R. Baumes. 2003. Quantitative determination of sulfur-containing wine odorants at sub parts per billion levels. 2. Development and application of a stable isotope dilution assay. J. Agric. Food Chem. 51:3243-3248.

Schreier, P., F. Drawert, and A. Junker. 1976. Identification of volatile constituents from grapes. J. Agric. Food Chem. 24:331-336.

Sefton, M.A., G.K. Skouroumounis, G.M. Elsey, and D.K. Taylor. 2011. Occurrence, sensory impact, formation, and fate of damascenone in grapes, wines, and other foods and beverages. J. Agric. Food Chem. 59:9717-9746.

Setkova, L., S. Risticevic, and J. Pawliszyn. 2007a. Rapid headspace solid-phase microextraction-gas chromatographic-time-of-flight mass spectrometric method for qualitative profiling of ice wine volatile fraction. I. Method development and optimization. J. Chromatogr., A $1147: 213-223$.

Setkova, L., S. Risticevic, and J. Pawliszyn. 2007b. Rapid headspace solid-phase microextraction-gas chromatographic-time-of-flight mass spectrometric method for qualitative profiling of ice wine volatile fraction. II: Classification of Canadian and Czech ice wines using statistical evaluation of the data. J. Chromatogr., A 1147:224-240.

Shao, Y., P. Marriott, R. Shellie, and H. Hügel. 2003. Solid-phase microextraction-Comprehensive two-dimensional gas chromatography of ginger (Zingiber officinale) volatiles. Flavour Fragr. J. 18:5-12.

Sidel, J.L., and H. Stone. 1993. The role of sensory evaluation in the food industry. Food Qual. Prefer. 4:65-73.

Siebert, T.E., H.E. Smyth, D.L. Capone, C. Neuwöhner, K.H. Pardon, G.K. Skouroumounis, M.J. Herderich, M.A. Sefton, and A.P. Pollnitz. 2005. Stable isotope dilution analysis of wine fermentation products by HS-SPME-GC-MS. Anal. Bioanal. Chem. 381:937-947.

Silva Ferreira, A.C., and P. Guedes de Pinho. 2003. Analytical method for determination of some aroma compounds on white wines by solid phase microextraction and gas chromatography. J. Food Sci. $68: 2817-2820$

Silva Ferreira, A.C., and P. Guedes de Pinho. 2004. Nor-isoprenoids profile during port wine ageing-Influence of some technological parameters. Anal. Chim. Acta 513:169-176.

Sivertsen, H.K., F.M. Dewey, and H. Heymann. 2005. Relationship between sensory descriptive analysis and levels of Botrytis antigens in dessert wines. Am. J. Enol. Vitic. 56:330-335.

Skogerson, K., R. Runnebaum, G. Wohlgemuth, J. de Ropp, H. Heymann, and O. Fiehn. 2009. Comparison of gas chromatography-coupled time-of-flight mass spectrometry and ${ }^{1} \mathrm{H}$ nuclear magnetic resonance spectroscopy metabolite identification in white wines from a sensory study investigating wine body. J. Agric. Food Chem. 57:6899-6907.

Skouroumounis, G.K., and M.A. Sefton. 2000. Acid-catalyzed hydrolysis of alcohols and their $\beta$-D-glucopyranosides. J. Agric. Food Chem. 48:2033-2039. 
Skouroumounis, G., and M. Sefton. 2002. The formation of $\beta$-damascenone in wine. In Carotenoid-Derived Aroma Compounds. P. Winterhalter and R. Rouseff (eds.), pp. 241-254. ACS Symp. Series 802. Am. Chemical Society, Washington, DC.

Skouroumounis, G.K., M.J. Kwiatkowski, I.L. Francis, H. Oakey, D.L. Capone, B. Duncan, M.A. Sefton, and E.J. Waters. 2005a. The impact of closure type and storage conditions on the composition, colour and flavour properties of a Riesling and a wooded Chardonnay wine during five years' storage. Aust. J. Grape Wine Res. 11:369-377.

Skouroumounis, G.K., M.J. Kwiatkowski, I.L. Francis, H. Oakey, D.L. Capone, Z. Peng, B. Duncan, M.A. Sefton, and E.J. Waters. 2005b. The influence of ascorbic acid on the composition, colour and flavour properties of a Riesling and a wooded Chardonnay wine during five years' storage. Aust. J. Grape Wine Res. 11:355-368.

Smilde, A.K., M.M.W.B. Hendriks, J.A. Westerhuis, and H.C.J. Hoefsloot. 2013. Data processing metabolomics. In Metabolomics in Practice. M. Lämmerhofer and W. Weckwerth (eds.), pp. 261-284. Wiley-VCH, Weinheim, Germany.

Soden, A., I.L. Francis, H. Oakey, and P.A. Henschke. 2000. Effects of co-fermentation with Candida stellata and Saccharomyces cerevisiae on the aroma and composition of Chardonnay wine. Aust. J. Grape Wine Res. 6:21-30.

Sponholz, W.R., A. Hoffmann, F. David, and P. Sandra. 2001. Detection of corkiness in wine by analysis of 2,4,6-trichloroanisole with stir bar sorptive extraction (SBSE) and thermal desorption GC/MS. Mitt. Klosterneuburg 51:248-253.

Steffen, A., and J. Pawliszyn. 1996. Analysis of flavor volatiles using headspace solid-phase microextraction. J. Agric. Food Chem. 44:2187-2193.

Stein, S.E. 1999. An integrated method for spectrum extraction and compound identification from gas chromatography/mass spectrometry data. J. Am. Soc. Mass Spectr. 10:770-781.

Strauss, C.R., P.R. Gooley, B. Wilson, and P.J. Williams. 1987. Application of droplet countercurrent chromatography to the analysis of conjugated forms of terpenoids, phenols, and other constituents of grape juice. J. Agric. Food Chem. 35:519-524.

Stummer, B.E., I.L. Francis, A.J. Markides, and E.S. Scott. 2003. The effect of powdery mildew infection of grape berries on juice and wine composition and on sensory properties of Chardonnay wines. Aust. J. Grape Wine Res. 9:28-39.

Stummer, B.E., I.L. Francis, T. Zanker, K.A. Lattey, and E.S. Scott. 2005. Effects of powdery mildew on the sensory properties and composition of Chardonnay juice and wine when grape sugar ripeness is standardised. Aust. J. Grape Wine Res. 11:66-76.

Tikunov, Y., A. Lommen, C.H.R. de Vos, H.A. Verhoeven, R.J. Bino, R.D. Hall, and A.G. Bovy. 2005. A novel approach for nontargeted data analysis for metabolomics. Large-scale profiling of tomato fruit volatiles. Plant Physiol. 139:1125-1137.

Varming, C., M.L. Andersen, and L. Poll. 2004. Influence of thermal treatment on black currant (Ribes nigrum L.) juice aroma. J. Agric. Food Chem. 52:7628-7636.

Varming, C., M.L. Andersen, and L. Poll. 2006. Volatile monoterpenes in black currant (Ribes nigrum L.) juice: Effects of heating and enzymatic treatment by $\beta$-glucosidase. J. Agric. Food Chem. 54:2298-2302.

Verhoeven, H., T. Beuerle, and W. Schwab. 1997. Solid-phase microextraction: Artefact formation and its avoidance. Chromatographia 46:63-66

Vestner, J., S. Malherbe, M. du Toit, H.H. Nieuwoudt, A. Mostafa, T. Górecki, A.G.J. Tredoux, and A. De Villiers. 2011. Investigation of the volatile composition of pinotage wines fermented with different malolactic starter cultures using comprehensive two-dimensional gas chromatography coupled to time-of-flight mass spectrometry (GC $\times$ GC-TOF-MS). J. Agric. Food Chem. 59:12732-12744.

Vilanova, M., and F. Vilariño. 2006. Influence of geographic origin on aromatic descriptors of Spanish Albariño wine. Flavour Fragr. J. 21:373-378

Villamor, R.R., and C.F. Ross. 2013. Wine matrix compounds affect perception of wine aromas. Ann. Rev. Food Sci. Technol. 4:1-20.

Voilley, A., and S. Lubbers. 1999. Flavor-matrix interactions in wine. In Chemistry of Wine Flavor. A.L. Waterhouse and S.E. Ebeler (eds.), pp. 217-229. ACS Symp. Series 714. Am. Chemical Society, Washington, DC.

Webb, A.D., and R.E. Kepner. 1961. Fusel oil analysis by means of gas-liquid partition chromatography. Am. J. Enol. Vitic. 12:51-59.

Weldegergis, B.T., A.M. Crouch, T. Górecki, and A. de Villiers. 2011a. Solid phase extraction in combination with comprehensive two-dimensional gas chromatography coupled to time-of-flight mass spectrometry for the detailed investigation of volatiles in South African red wines. Anal. Chim. Acta 701:98-111.

Weldegergis, B.T., A.D. Villiers, C. McNeish, S. Seethapathy, A. Mostafa, T. Górecki, and A.M. Crouch. 2011b. Characterisation of volatile components of Pinotage wines using comprehensive twodimensional gas chromatography coupled to time-of-flight mass spectrometry (GC x GC-TOFMS). Food Chem. 129:188-199.

Wilkinson, K.L., et al. 2011. Comparison of methods for the analysis of smoke related phenols and their conjugates in grapes and wine. Aust. J. Grape Wine Res. 17:S22-S28.

Williams, P.J. 1993. Hydrolytic flavor release in fruit and wines through hydrolysis of nonvolatile precursors. In Flavor Science: Sensible Principles and Techniques. T. Acree and R. Teranishi (eds.), pp. 287-308. Am. Chemical Society, Washington, DC.

Williams, P.J., W. Cynkar, I.L. Francis, J.D. Gray, P.G. Iland, and B.G. Coombe. 1995. Quantification of glycosides in grapes, juices, and wines through a determination of glycosyl glucose. J. Agric. Food Chem. 43:121-128.

Williams, P.J., C.R. Strauss, B. Wilson, and R.A. Massy-Westropp. 1982. Use of $\mathrm{C}_{18}$ reversed-phase liquid chromatography for the isolation of monoterpene glycosides and nor-isoprenoid precursors from grape juice and wines. J. Chromatogr., A 235:471-480.

Winterhalter, P., M.A. Sefton, and P.J. Williams. 1990. Two-dimensional GC-DCCC analysis of the glycoconjugates of monoterpenes, norisoprenoids, and shikimate-derived metabolites from Riesling wine. J. Agric. Food Chem. 38:1041-1048.

Wood, C., et al. 2008. From wine to pepper: Rotundone, an obscure sesquiterpene, is a potent spicy aroma compound. J. Agric. Food Chem. 56:3738-3744

Yang, S., J.C. Hoggard, M.E. Lidstrom, and R.E. Synovec. 2013. Gas chromatography and comprehensive two-dimensional gas chromatography hyphenated with mass spectrometry for targeted and nontargeted metabolomics. In Metabolomics in Practice. M. Lämmerhofer and W. Weckwerth (eds.), pp. 69-92. Wiley-VCH, Weinheim, Germany.

Zhang, Z., and J. Pawliszyn. 1993. Headspace solid-phase microextraction. Anal. Chem. 65:1843-1852.

Zoecklein, B.W., L.S. Douglas, and Y.W. Jasinski. 2000. Evaluation of the phenol-free glycosyl-glucose determination. Am. J. Enol. Vitic. 51:420-423.

Zoecklein, B.W., T.K. Wolf, S.E. Duncan, J.E. Marcy, and Y. Jasinski. 1998. Effect of fruit zone leaf removal on total glycoconjugates and conjugate fraction concentration of Riesling and Chardonnay (Vitis vinifera L.) grapes. Am. J. Enol. Vitic. 49:259-265. 